\title{
A Model for the Yield Strength of Overaged Al-Zn-Mg-Cu Alloys
}

\author{
M.J. Starink* and S.C. Wang \\ Materials Research Group, School of Engineering Sciences, University of Southampton, \\ Southampton S017 1BJ, UK
}

Keywords: 7xxx Al alloy, Physically-based modelling, Overageing, Precipitation, Schmid factors

\begin{abstract}
A model for the yield strength of multi-component alloys is presented and applied to overaged $\mathrm{Al}-\mathrm{Zn}-\mathrm{Mg}-\mathrm{Cu}$ alloys (7xxx series). The model is based on an approximation of the strengthening due to precipitate by-passing during precipitate coarsening and takes account of ternary and higher order systems. It takes account of the influence of supersaturation on precipitation rates and of volume fraction on coarsening rates, as well crystallographic texture and recrystallisation. The model has been successfully used to fit and predict the yield strength data of $21 \mathrm{Al}-\mathrm{Zn}-\mathrm{Mg}-\mathrm{Cu}$ alloys, with compositions spread over the whole range of commercial alloying compositions, and which were aged for a range of times and temperatures to produce yield strengths ranging from 400 to $600 \mathrm{MPa}$. All but one of the microstructural and reaction rate parameters in the model are determined on the basis of microstructural data, with one parameter fitted to yield strength data. The resulting accuracy in predicting unseen proof strength data is $14 \mathrm{MPa}$. In support of the model, microstructures and phase transformations of 7xxx alloys were studied by a range of techniques, including differential scanning calorimetry (DSC), electron backscatter diffraction (EBSD) in an SEM with a field emission gun (FEG-SEM).
\end{abstract}

* Corresponding author. Tel.: 00-44-23-80595094; Fax: 00-44-23-80593016;

E-mail address: M.J.Starink@soton.ac.uk 


\section{Introduction}

Since the 1940s significant progress has been made in quantitatively predicting the individual strengthening effects in simple metallic alloy systems, such as solution strengthening, strengthening due to coherent particles, dispersion strengthening, grain boundary strengthening, etc. In complex heat treatable commercial alloys, a superposition of a multitude of strengthening effects occurs, and the prediction of the yield strength as a function of composition, thermo-mechanical processing, and heat treatment attracts great interests, both from commercial and academic perspective. Recent published literature on modelling of the yield strength of Al based alloys [1,2,3,4,5,6,7] provide a variety of modelling approaches, e.g. physically-based models of varying complexity and adaptive numeric analysis have been developed to model the complex relations between thermo-mechanical treatment, ageing treatment, microstructural changes, mechanical properties, etc. Especially the physically-based models have progressed quickly over the past 15 years, providing models for single precipitation strengthened alloys [1], groups of binary precipitation strengthened alloys [2], alloys containing 2 and more precipitating phases [5], strength anisotropy [6]. Existing published models, however, cannot predict yield strengths of sets of ternary and higher order alloys with different compositions, in which the composition of the strengthening precipitates is variable. This is relevant for instance for $\mathrm{Al}-\mathrm{Zn}-\mathrm{Mg}-\mathrm{Cu}$ alloys (7xxx class) because in these alloys the composition of the strengthening phase depends on alloy composition [8].

Modelling of strength of heat treatable $\mathrm{Al}-\mathrm{Zn}-\mathrm{Mg}-\mathrm{Cu}$ aluminium alloys is especially important because yield strength is critical in applications of these high strength Al based alloys. It is the precipitation strengthening which provides by far the strongest contribution to the strength of aged $\mathrm{Al}-\mathrm{Zn}-\mathrm{Mg}-\mathrm{Cu}$ alloys. The main precipitation sequence which dominates hardening in most commercially used $7 \mathrm{xxx}$ alloys is $[3,9,10]$ :

$$
\mathrm{SSS} \alpha \rightarrow \text { GP zones } \rightarrow \eta^{\prime} \rightarrow \eta
$$

where SSS $\alpha$ represents supersaturated solid solution, GP zones are Guinier Preston zones, $\eta$ is a quaternary phase containing $\mathrm{Al}, \mathrm{Zn}, \mathrm{Mg}$ and $\mathrm{Cu}$, which can be considered to be based on a solid solution of $\mathrm{MgZn}_{2}$ with $\mathrm{AlCuMg}$ components (i.e. $\mathrm{Mg}(\mathrm{Zn}, \mathrm{Al}, \mathrm{Mg})_{2}$ or $\mathrm{Mg}\left(\mathrm{Zn}_{2}, \mathrm{AlMg}\right)$ ) [11]. The compositions of the quaternary phases $\eta^{\prime}$ and $\eta$ is dependent on heat treatment and alloy composition [8]. Other sequences involving $\mathrm{S}\left(\mathrm{Al}_{2} \mathrm{CuMg}\right)$ and $\mathrm{T}$ (a quaternary phase based on $\mathrm{Mg}_{3} \mathrm{Zn}_{3} \mathrm{Al}_{2}$ ) can occur at temperatures in excess of $200^{\circ} \mathrm{C}$, but are generally thought not to contribute to strengthening for commercially applied heat treatments, which generally involve ageing treatments below $180^{\circ} \mathrm{C}$. The most recent work indicates that in the peak-aged condition (T6), the main precipitate phases are a mixture of $\eta^{\prime}$ and $\eta$ [12], whilst in overaged conditions (T7) the main precipitate phase is $\eta[13,14]$. 
Most commercial 7xxx alloys can be categorized in two groups depending on the type of grain structure controlling element that is added. $\mathrm{Zr}$ containing alloys will contain $\beta^{\prime}$ phase $\left(\mathrm{Al}_{3} \mathrm{Zr}, \mathrm{L}_{2}\right.$ structure) particles, whilst $\mathrm{Cr}$ containing alloys will generally contain $\mathrm{Al}_{7} \mathrm{Cr}$ particles. In aluminium metallurgy, these grain structure controlling particles are generally called dispersoids. The type of dispersoids will influence the recrystallisation and quench sensitivity of the alloy. Through varying recrystallisation, the dispersoids also influence the texture and the related anisotropy.

In the present paper we will present a model that is designed for modelling and predicting strength in overaged multi-component alloys, in which the composition of the precipitates is variable, and closely related to the alloy composition. The model is mostly based on physical principles, but to accommodate the complexities introduced by the multi-component precipitates with varying composition, additional approximations are included. The model will be tested by modelling the strengths of a wide range of $\mathrm{Al}-\mathrm{Zn}-\mathrm{Mg}-\mathrm{Cu}$ alloys, with compositions spanning the range of most of the commercially used alloy compositions. To calibrate the parameters in the model and to verify its physical foundations, the microstructure of the alloys is investigated using optical microscopy, differential scanning calorimetry (DSC), conventional scanning electron microscopy (SEM) along with energy dispersive X-ray spectrometry (EDS), electron backscatter diffraction (EBSD) in an SEM with a field emission gun (FEG-SEM).

\section{Experimental}

\subsection{Alloys}

To calibrate and test models, a database containing $0.2 \%$ proof strengths (measured in the rolling direction) of $21 \mathrm{Al}-\mathrm{Zn}-\mathrm{Mg}-\mathrm{Cu}$ alloys aged for various times at 164 and $172^{\circ} \mathrm{C}$ after heating at $20^{\circ} \mathrm{C} / \mathrm{h}$ to the ageing temperature is used. All alloys were produced at QinetiQ (formerly DERA), Farnborough, UK. All alloys were processed using an identical process. Ingots were cast using conventional casting procedures, and after stress relaxation and homogenisation, ingots were cut and hot worked in several stages. The final stage was hot rolling to $25 \mathrm{~mm}$ thick plates of about $1 \mathrm{~m}$ length and $0.2 \mathrm{~m}$ width. All alloy plates were solution treated at $475^{\circ} \mathrm{C}$ for $1 \mathrm{~h}$ and quenched and subsequently aged. (No stretching was applied.) Compositions of selected alloys are presented in the results section and the figures, but some of the composition data in the database is confidential. There are two groups of alloys, one consists of alloys that contain $\mathrm{Zr}$ as dispersoid forming element and the second group consists of alloys that contain $\mathrm{Cr}$ as dispersoid forming element. The database contains five $\mathrm{Cr}$-containing and $16 \mathrm{Zr}$ containing alloys. The compositions of the $\mathrm{Zr}$ containing alloys fall broadly within in the range of typical $\mathrm{Zr}$ containing aerospace alloys 7010 , $7 \times 50$ and 7040 (for composition ranges see Table 1, some of the present alloys have $\mathrm{Cu}$ contents 
slightly lower and $\mathrm{Mg}$ and $\mathrm{Zn}$ contents slightly higher than these composition ranges) and compositions of the Cr containing alloys fall within the composition range of the $\mathrm{Cr}$ containing alloy $7 \times 75$. The Zr-containing alloys contain $0.02 \% \mathrm{Ti}$ and $0.12 \% \mathrm{Zr}$ (all in wt\%). The Crcontaining alloys contain $0.02 \% \mathrm{Ti}$ and $0.2 \% \mathrm{Cr}$. For all alloys, $99.90 \%$ aluminium was used as base to ensure comparable, low impurity contents. Measured gross Fe contents, $x_{F e}^{g}$, of the alloys are between 0.05 and $0.08 \mathrm{wt} \%$ and Si contents, $x_{S i}^{g}$, are between 0.02 and $0.03 \mathrm{wt} \%$. Further details of alloy production are given in [15].

For all ageing treatment / alloy combinations 2 samples were tested. In a statistical analysis of the data gathered it was found that proof strengths after one single (intermediate) ageing procedure often produced anomalous results and it was decided to omit all data for this treatment from the database, thus reducing the total amount of data by $12 \%$. The database on these two groups of alloys contained a total of 66 alloy/ageing combinations, with at least 3 ageing treatments for each of the 21 alloys.

\subsection{Microstructural Analysis}

Selected heat treated alloys were studied by using optical microscopy, DSC, SEM along with EDS, EBSD in a FEG-SEM and transmission electron microscopy (TEM).

For optical microscopy and SEM, specimens were ground and subsequent polishing was performed using $6 \mu \mathrm{m}, 1 \mu \mathrm{m}$ and finally $1 / 4 \mu \mathrm{m}$ diamond paste. For grain structure examination in the optical microscope, samples were etched in $10 \mathrm{~cm}^{3} \mathrm{H}_{3} \mathrm{PO}_{4}$ plus $90 \mathrm{~cm}^{3}$ distilled water at $50^{\circ} \mathrm{C}$ for one minute. SEM work was conducted on a Jeol JSM-6400 SEM. Mostly backscattered electron mode was used. Different areas on the TS sections were scanned to reveal the existing particles. Chemical compositions of various particles in the samples were measured using EDS.

The EBSD specimens were ground and polished and subsequently electro-polished using a solution of $33 \% \mathrm{HNO}_{3}$ and $67 \%$ methanol at a temperature of $-30^{\circ} \mathrm{C}$. Orientation measurements were taken in a JEOL FEG-SEM 6500F using an automated EBSD system (Channel 5 software from HKL, Denmark). Step size was 1 or $2 \mu \mathrm{m}$. Success rate of identification of Kikuchi patterns was $80-90 \%$.

TEM was performed on a JEOL JEM 2000FX transmission electron microscope. The TEM samples were prepared by cutting a thin slice $(\sim 0.3 \mathrm{~mm})$, punching a $3 \mathrm{~mm}$ diameter disc and grinding it to a thickness of about $0.15 \mathrm{~mm}$. Subsequent electropolishing was performed with a twin jet electropolisher using a solution of $30 \% \mathrm{HNO}_{3}$ and $70 \%$ methanol maintained at a temperature of between $-20^{\circ} \mathrm{C}$ and $-30^{\circ} \mathrm{C}$. 
DSC experiments were performed using a Shimadzu DSC-50 (heat-flux type) calorimeter. The heating rate was $10^{\circ} \mathrm{C} / \mathrm{min}$. Further details of the DSC experimental procedures are presented elsewhere $[13,16]$. Presented DSC curves show the heat flows after correction for baseline and heat capacity effects, i.e. they represent the heat flow due to reactions in the sample, with the horizontal line of zero heat flow representing points where no net heat flow due to reactions occurs.

\section{The strength model}

\subsection{Overview of the main strengthening contributions}

In this chapter, a model applicable to yield strength of Al-Zn-Mg-Cu 7xxx alloys will be described. In the model, four contributions to the critical resolved shear stress (CRSS) of grains will be considered: the intrinsic CRSS, $\Delta \tau_{o}$, the solid solution contribution, $\Delta \tau_{s s}$, the contribution due to dislocations in the grain, $\Delta \tau_{d}$, and the contribution due to precipitation strengthening, $\Delta \tau_{p p t}$. The obstacle strengths responsible for $\Delta \tau_{d}$ and $\Delta \tau_{p p t}$ are of a similar magnitude and hence should apply a superposition rule. Here we will use the phenomenological superposition approximation for obstacles of similar strengths $[5,17,18]$ :

$$
\Delta \tau_{d \& p p t}{ }^{2}=\Delta \tau_{d}{ }^{2}+\Delta \tau_{p p t}{ }^{2}
$$

The obstacle strength for solid solution hardening is much smaller than that for precipitation and dislocation hardening, and hence we can use a linear summation for that contribution [5,17]. Thus we obtain the CRSS of the grains, $\tau_{\text {tot }}$ :

$$
\tau_{\text {tot }}(t)=\Delta \tau_{0}+\Delta \tau_{s s}+\Delta \tau_{d \& p p t}
$$

where $\Delta \tau_{s s}$ is a function of solute concentration at equilibrium at the ageing temperature, and $\Delta \tau_{o}$ is the CRSS of (commercially) pure Al. The largest contribution to the strength of 7xxx alloys is provided by $\Delta \tau_{p p t}$, and the derivation of a model for that will be the subject of sections 3.4 and 3.5.

In polycrystalline materials each grain will in principle have a different orientation and plastic deformation of the alloy will occur through plastic deformation of the individual grains by slip on specific slip systems. In the absence of other strengthening mechanisms, the (macroscopic) yield strength of a polycrystalline metal has been related to the CRSS of the crystals via various models [19,20,21,22]. In these approaches the (macroscopic) yield strength can generally be related to the CRSS by an equation of the type: 


$$
\sigma_{y}=\Delta \sigma_{g b}+M \tau_{\text {tot }}
$$

Where $\Delta \sigma_{g b}$ is the strengthening due to the presence of (sub-)grain boundaries and $M$ is a factor that depends on texture (sometimes referred to as the Taylor factor) and the orientation of the tensile axis relative to the main axes of the worked specimen.

\subsection{Undissolved Particles}

First, we calculate the amount of the alloying elements that do not dissolve during solution treatment. In 7xxx alloys, phases that are not fully dissolved during solution treatment can include the $\mathrm{S}\left(\mathrm{Al}_{2} \mathrm{CuMg}\right), \mathrm{T}$ (based on $\mathrm{Mg}_{3} \mathrm{Zn}_{3} \mathrm{Al}_{2}$, with some $\mathrm{Cu}$ dissolved in it), $\mathrm{Al}_{7} \mathrm{Cu}_{2} \mathrm{Fe}$ and $\mathrm{Mg}_{2} \mathrm{Si}$ phases [16,23,24], where the presence of the latter two is caused by impurities $\mathrm{Fe}$ and $\mathrm{Si}$. The amounts of each phase present can be calculated/predicted using thermodynamic models $[25,26]$ or phase diagrams [27]. For the present work, $\mathrm{T}$ and $\mathrm{Mg}_{2} \mathrm{Si}$ are neglected because previous work $[15,16]$ has indicated that they are either not present or only present in limited amounts in commercial $7 \mathrm{xxx}$ alloys. To calculate the amounts of $\mathrm{S}$ and $\mathrm{Al}_{7} \mathrm{Cu}_{2} \mathrm{Fe}$, we will use simplified thermodynamic models, which were presented in detail elsewhere [28]. Here the main equations will be presented.

The solubility of $\mathrm{Fe}$ in $\mathrm{Al}$ is not significantly influenced by $\mathrm{Cu}$ or $\mathrm{Mg}$ additions [29] and the amount of $\mathrm{Al}_{7} \mathrm{Cu}_{2} \mathrm{Fe}$ present in the alloy after solution treatment is given by:

$$
y_{\mathrm{Al} 7 \mathrm{Cu} 2 \mathrm{Fe}}=10\left(x_{\mathrm{Fe}}^{g}-c_{\mathrm{Fe}}\left(T_{\text {sol }}\right)\right)
$$

where $y_{X}$ stands for the atomic fraction of phase $\mathrm{X}$ (in this case $\mathrm{Al}_{7} \mathrm{Cu}_{2} \mathrm{Fe}$ ), $x_{Y}^{g}$ stands for the gross content of alloying/impurity element $\mathrm{Y}$ (in this case Fe), $c_{Y}$ is the solubility of element $\mathrm{Y}$ in the Al rich phase and $T_{\text {sol }}$ is the solution treatment temperature. The amount of $\mathrm{S}$ phase is obtained using a regular solution model [30,31], which has been shown to be a good approximation for the solvus of $\mathrm{S}$ phase in Al-Zn-Mg-Cu alloys [16]. In this model the solvus related to an intermetallic phase $\mathrm{M}_{\mathrm{m}} \mathrm{A}_{\mathrm{a}} \mathrm{B}_{\mathrm{b}} \mathrm{C}_{\mathrm{c}}(\mathrm{M}$ is the main constituent of the alloy, and $\mathrm{A}, \mathrm{B}, \mathrm{C}$ are the alloying elements) is given by:

$$
\left(c_{A}\right)^{a}\left(c_{B}\right)^{b}\left(c_{C}\right)^{c}=c_{1} \exp \left[\frac{-\Delta H_{\text {sol }}}{R T}\right]
$$

where $\Delta H_{\text {sol }}$ is the enthalpy of formation per $\mathrm{M}_{\mathrm{m}} \mathrm{A}_{\mathrm{a}} \mathrm{B}_{\mathrm{b}} \mathrm{C}_{\mathrm{c}}$ unit, $R$ is the gas constant, $T$ is the temperature and $c_{1}$ is a constant. For the $\mathrm{S}$ phase, $\Delta H_{\text {sol }}^{s}$ has been determined before [30,31], and by combining solvus data at $460^{\circ} \mathrm{C}$ [32] with $\Delta H_{\text {sol }}^{s}$, the $\mathrm{S}$ solvus as a function of the temperature can 
be estimated [33]. After calculation of $y_{s}$ and $y_{\mathrm{Al}_{7} \mathrm{Cu}_{2} \mathrm{Fe}}$ the fractions of the elements dissolved in the Al-rich phase after solution treatment, $x_{Y}$, can be obtained from:

$$
\begin{aligned}
& x_{\mathrm{Cu}}(t=0)=\frac{x_{\mathrm{Cu}}^{g}-\frac{2}{10} y_{\mathrm{Al}_{7} \mathrm{Cu} \mathrm{u}_{2} \mathrm{Fe}}-\frac{1}{4} y_{S}}{1-y_{\mathrm{Al}_{7} \mathrm{Cu}_{2} \mathrm{Fe}}-y_{S}} \\
& x_{\mathrm{Mg}}(t=0)=\frac{x_{\mathrm{Mg}}^{g}-\frac{1}{4} y_{S}}{1-y_{\mathrm{Al}_{7} \mathrm{Cu} u_{2} \mathrm{Fe}}-y_{S}} \\
& x_{Z n}(t=0)=\frac{x_{\mathrm{Zn}}^{g}}{1-y_{\mathrm{Al}_{7} \mathrm{Cu} \mathrm{F}_{2} \mathrm{Fe}}-y_{S}}
\end{aligned}
$$

and similar for Si and Fe (see [28]).

\subsection{Microstructure development in pseudo-binary alloys}

The (semi-) equilibrium state

For binary or pseudo-binary alloys the equilibrium volume fractions of precipitates and fractions dissolved in the matrix can be approximated in a straightforward fashion using the regular solution model $[1,16]$. Thus, the amount dissolved after completion of precipitation, $c_{o}$, is given by:

$$
c_{0}=c_{s} \exp \left(-\frac{Q_{s}}{R}\left[\frac{1}{T}-\frac{1}{T_{s}}\right]\right)
$$

where $c_{S}$ is the solvus boundary (the initial concentration of the solid solution), $Q_{s}$ is the free energy of solution, $T_{s}$ is the solvus temperature, $R$ is the gas constant. The latter equation can be derived from the full expression for non pseudo-binary alloys. For instance, the solvus of $\eta^{\prime}$ for ternary Al$\mathrm{Mg}-\mathrm{Cu}$ alloys can be approximated as [28]:

$$
\left(c_{Z n}\right)^{2} \times\left(c_{M g}\right)=A_{0} \exp \left(\frac{-\Delta H_{\text {sol }}^{\eta^{\prime}}}{R T}\right)
$$

where $c_{Z n}$ and $c_{M g}$ are equilibrium concentrations of alloying elements $\mathrm{Zn}$ and $\mathrm{Mg}$ in the Al-rich phase, $\Delta H_{\text {sol }}^{\eta^{\prime}}$ is the solution enthalpy of $\eta^{\prime}$ which equals $26.6 \mathrm{~kJ} / \mathrm{mol}$ [28], and $\mathrm{A}_{0}$ is a constant. For a pseudo binary Al-Zn-Mg alloy $c_{Z n}=2 c_{M g}$, and hence: 


$$
c_{Z n}=2 c_{M g}=\left(A_{o} 2\right)^{1 / 3} \exp \left(\frac{-\Delta H_{s o l}^{\eta^{\prime}}}{3 R T}\right)
$$

Thus, in this case, $Q_{s}=1 / 3 \Delta H_{\text {sol }}^{\eta^{\prime}}=8.9 \mathrm{~kJ} / \mathrm{mol}$. In fact it can be shown that in general, for a phase $M_{m} A_{a} B_{b} C_{c}$, for which the solvus is given by the regular solution model (Eq. 5), $Q_{s}$ is best approximated as $\Delta H_{\text {sol }}^{M A B b C C} /(\mathrm{a}+\mathrm{b}+\mathrm{c})$.

The volume fraction of precipitates that can form at a particular ageing temperature, $f_{o}(T)$, is given by:

$$
f_{0}=f_{\max } \frac{c_{s}-c_{0}}{c_{s}}
$$

Where $f_{\max }$ is the maximum value that $f_{o}$ can take, i.e. when all alloying elements would precipitate. In calculating $f_{\max }$ for the $\mathrm{Al}-\mathrm{Zn}-\mathrm{Mg}-\mathrm{Cu}$ alloys we take account of $\mathrm{Al}$ in the precipitate by taking the Al fraction $\mathrm{m} /(\mathrm{a}+\mathrm{b}+\mathrm{c})$ equal to the one experimentally determined from APFIM for an Al-6.1Zn$2.35 \mathrm{Mg}-0.1 \mathrm{Zr}$ alloy aged $10 \mathrm{~h}$ at $160^{\circ} \mathrm{C}: \mathrm{m} /(\mathrm{a}+\mathrm{b}+\mathrm{c})=0.29$ [34]. As the atomic density of $\eta$ is equal to that of FCC Al, the atomic fraction of precipitate is equal to the volume fraction [34].

\section{$\underline{\text { Precipitation }}$}

The transformed fraction of precipitates during ageing can be described by the Starink-Zahra (SZ) model for nucleation and growth $[35,36]$ :

$$
\alpha(T, t)=1-\left(\frac{[K(T) t]^{n}}{\eta_{i}}+1\right)^{-\eta_{i}}
$$

where $\alpha$ is the transformed fraction, $n$ is the reaction exponent, $\eta_{i}$ is the impingement exponent and $K(T)$ is the rate constant which can be expressed by an Arrhenius relation:

$$
K(T)=k \exp \left(-\frac{E}{R T}\right)
$$

where $E$ is the activation energy of the reaction, $R$ is the gas constant and $k$ is a pre-exponential factor. It is noted that for $\eta_{i} \rightarrow \infty$, the SZ model is identical to the Johnson-Mehl-AvramiKolmogorov (JMAK) model.

Precipitation rates will in general depend on the supersaturation $\left(C_{s}-C_{o}\right)$ : the higher the supersaturation, the higher the precipitation rate. One can attempt to capture this effect using 
nucleation rate theory, but here we will use a simplified treatment. If we assume that supersaturation has no influence on the size of precipitates formed, then a higher concentration of solute enhances precipitation rates because the average interparticle distance, $d$, decreases with increasing solute content. We can derive the following rules of proportionality. From consideration of the total amount precipitated, the average volume of the precipitates and the density of precipitates we can derive:

$$
c_{s}-c_{o} \propto \frac{\left(\overline{l_{o}}\right)^{3}}{d^{3}}
$$

As the diffusion distance is proportional to $\sqrt{D t}$, where $D$ is the diffusion rate, we can derive:

$$
t \propto \frac{d^{2}}{D} \propto \frac{\left(c_{s}-c_{o}\right)^{-2 / 3}}{D}
$$

Thus the effect of accelerating precipitation with increasing supersaturation can be accounted for by taking:

$$
k=\left(c_{s}-c_{o}\right)^{2 / 3} k_{o}
$$

where $k_{o}$ is a constant.

\section{Coarsening}

To model the evolution of the average size of the precipitates in the transition from the growth stage to the coarsening stage a novel, simple analytical approach is used. Coarsening theory $[37,38,39,40]$ predicts that during coarsening the average radius of spherical precipitates increases according to:

$$
\bar{r}^{3}-\bar{r}_{o}^{3}=K_{r e l}\left(f_{o}\right) k_{c} t
$$

where $\bar{r}$ is the average radius of the precipitates, $\bar{r}_{o}$ is the average initial radius of the precipitates and $k_{c}$ is the rate constant for coarsening, which depends on temperature and interfacial energy, $K_{r e l}\left(f_{o}\right)$ is the relative rate constant for coarsening which describes the effect of volume fraction on the coarsening rate. Several authors have studied the effect of volume fraction on coarsening rate $[38,39,40]$; and we will here use the work of Marsh and Glicksman [38] who derived the values for $K_{\text {rel }}$ shown in Fig. 1. For $0.01<f_{o}<0.15$ the data is well represented by:

$$
K_{r e l} \cong 1+2 \sqrt{f_{o}}+1.83 f_{o}
$$


If it is assumed that the same coarsening equations are also valid for coarsening of precipitates with a fixed (non-spherical) shape we can write:

$$
\bar{l}_{c}^{3}(t)-\bar{l}_{0}^{3}=k_{c}(T) t
$$

where $l_{x, c}$ is the size of the precipitate in a particular direction during the coarsening stage (for instance the diameter or length of a rod, or the thickness of a plate). We will take:

$$
k_{c}(T)=k_{0, c} \exp \left(-\frac{E_{c o}}{R T}\right)
$$

where $E_{c o}$ is the activation energy for coarsening and $k_{o, c}$ is a constant.

It should be noted that details of the transition from growth to coarsening can fundamentally not be captured by SZ and JMAK type models, because they do not include a description of the range of particle sizes. However, the nucleation and growth stage is generally well separated from the coarsening stage, and due to this the average particle size is nearly constant in the transition stage and it is possible to devise a simple approximation for dealing with the transition by taking:

$$
\bar{l}(t)=\bar{l}_{g}(t)+\bar{l}_{c}(t)-\bar{l}_{0}
$$

where $\bar{l}_{g}(t)$ is the average size of the precipitates in nucleation and growth stages, $\bar{l}_{c}(t)$ is the average size of the precipitates during the coarsening stage and $\bar{l}_{0}$ is the size that is reached in the limit of $\alpha$ approaching 1. To calculate the evolution of the average size of the particles during the growth stage we will again use the assumption that the particles retain their shape throughout the growth process. We now need to distinguish two situations. If the amount of growing particles is constant during most of the growth stage (the so-called site saturation case), $n$ will equal $1 \frac{1}{2}$, and $\bar{l}_{g}(t)$ is given by $[4]$ :

$$
\bar{l}_{g}(t)=\bar{l}_{o} \alpha^{1 / 3}
$$

But if substantial continuous nucleation occurs, the average dimensions of the particles are influenced by the number of particles present. If the shape of the particles is identical, the dimensions of the particles should be proportional to the number of particles to the power $-1 / 3$. Combining this with the latter equation yields:

$$
\bar{l}_{g}(t)=\bar{l}_{o}\left(\frac{N_{\max }}{N(t)} \alpha\right)^{1 / 3}
$$


where $N(t)$ is the number of particles present, and $N_{\max }$ is the maximum number of particles present. In this continuous nucleation case, $n$ will equal $2 \frac{1}{2}$. In the early stages of the transformation, before significant impingement occurs, $N$ is proportional to $t$, i.e. $N$ will increase proportional to $\alpha^{1 / \mathrm{n}}$, and, when $\alpha$ increases the nucleation rate decrease because the volume available for nucleation will decrease as $(1-\alpha)$. We may conveniently approximate this situation by taking:

$$
N=C_{1}\left(\int(1-\alpha) d \alpha\right)^{1 / n}
$$

where $C_{1}$ is a constant proportional to the nucleation rate. Through integration and using the requirement $N(\alpha=1)=N_{\max }$ it can then be shown

$$
N=N_{\max }\left(2 \alpha-\alpha^{2}\right)^{1 / n}
$$

By combining the thermodynamic model for the solvi with the present kinetic model, the evolution of the volume fraction of precipitate $f(t)$, the average precipitate size $\bar{l}(t)$ and the concentrations of elements in solution $c(t)$ can be modelled.

\subsection{CRSS of grains of (pseudo-) binary alloys}

The solid solution contribution is taken as [1]:

$$
\Delta \tau_{s s}=C_{2} C_{0}^{2 / 3}
$$

where $C_{2}$ is a constant.

It has been shown by several authors that precipitation strengthening in $\mathrm{Al}-\mathrm{Zn}-\mathrm{Mg}(-\mathrm{Cu})$ alloys can be modelled by considering the dislocation bypassing mechanism only. The strengthening precipitates are close to a disc shape morphology and they lie parallel to $\{111\}$ planes. The expression for strengthening derived by Zhu and Starke [41] for these types of precipitates is ${ }^{\dagger}$ :

$$
\Delta \tau_{\text {prec }}=0.12 G \frac{b}{\left(l_{D} l_{t}\right)^{1 / 2}}\left[f^{1 / 2}+0.70\left(\frac{l_{D}}{l_{t}}\right)^{1 / 2} f+0.12\left(\frac{l_{D}}{l_{t}}\right) f^{3 / 2}\right] \ln \frac{0.079 l_{D}}{r_{\text {cut }}}
$$

where $r_{\text {cut }}$ is the inner cut-off radius for the calculation of the line tension, $l_{D}$ is the diameter of the discs, and $l_{t}$ is the thickness of the discs.

\footnotetext{
${ }^{\dagger}$ Note that in both $[2,41]$ this strengthening equation for $\{111\}$ discs contains typographical errors.
} 


\subsection{CRSS of grains: Multicomponent alloys}

The 7xxx alloys under consideration here are not pseudo-binary and the treatment described in the previous sections is only valid for selected alloys with fixed ratios of alloying elements. To derive a model that can be used for multi component alloys, we propose the following treatment. The mathematics can be presented in various ways, but in order to remain close to the treatment outlined in the previous chapters we will describe the model by first choosing a reference alloy, which is an alloy that has a composition close to the average of the range of alloys of concern. In this description the parameters and properties of the alloys are related to the reference alloy. The volume fraction of precipitates that can be obtained depends on the amount of solute that remains dissolved after completion of the ageing and takes the form:

$$
f_{0}=f_{\max , R}\left[\frac{c_{S}-c_{0}}{c_{S, R}}\right]
$$

where $f_{\max , R}$ is the final volume fraction that is obtained for the reference alloy, $c_{S, R}$ is the composition of that reference alloy, $c_{S}$ is the composition of the alloy (i.e. $c_{S}$ is different for each alloy), $c_{0}$ is the equilibrium (metastable equilibrium) concentration and is expressed as:

$$
c_{0}=c_{S} \exp \left[-\frac{Q_{S}}{R}\left(\frac{1}{T}-\frac{1}{T_{S, R}}\right)\right]
$$

where $T_{S, R}$ is the solvus temperature in the reference alloy, and $Q_{S}$ is the free energy of the solute. In other words, $Q_{S}$ is the enthalpy of formation of the precipitate, also indicated as $\Delta H_{\text {sol }}$. We consider that for practical purposes it may be sufficient to simplify and assume that $c_{S}$ is a linear combination of the concentrations of the main alloying elements:

$$
c_{S}=x_{A}+B_{B} x_{B}+B_{C} x_{C}+\ldots \text { etc }
$$

where $A, B, C$ are the main alloying elements and $B_{B}, B_{C}$ etc are fittable parameters. For $7 x x x$ type alloys, we can apply this by taking $\mathrm{A}=\mathrm{Zn}, \mathrm{B}=\mathrm{Mg}$ and $\mathrm{C}=\mathrm{Cu}$.

In general, the $B_{X}$ parameters will need to be obtained by fitting. However, in alloys in which the ratios of alloying elements in the main precipitate are similar to the ratios of those alloying elements in the matrix, the $B_{X}$ parameters referring to those elements are expected to be unity. In fact this appears to broadly hold true for the $\mathrm{Mg}: \mathrm{Zn}$ ratio in $\eta^{\prime}$ and $\eta$ precipitates in Al-Zn-Mg-Cu alloys [8], 
and hence it is expected that $B_{M g}=1$. Also $\mathrm{Cu}: \mathrm{Zn}$ ratios of precipitates appear to be broadly in line with the $\mathrm{Cu}: \mathrm{Zn}$ ratio of the matrix [8] and hence we can expect that $B_{C u}$ is also close to unity.

\subsection{Grain structure, texture and Schmid factors.}

To obtain the yield strengths of polycrystalline materials with known CRSS the grain boundary strengthening contribution and the $M$ factor (sometimes called Taylor factor) needs to be determined. In our alloys, grain boundary strengthening is small as compared to precipitation strengthening and the following expression for grain boundary strengthening is sufficiently accurate $[42,43]$ :

$$
\Delta \sigma_{g b}=\alpha_{2} G b\left[\left(1-f_{\operatorname{Re} X}\right)\left(\frac{1}{\delta}\right)+f_{\operatorname{Re} X}\left(\frac{1}{D}\right)\right] \cong \alpha_{2} G b\left(1-f_{\operatorname{Re} X}\right)\left(\frac{1}{\delta}\right)
$$

where $G$ is the shear modulus of $\mathrm{Al}, b$ is the Burgers vector, $f_{\operatorname{ReX}}$ is the recrystallised volume fraction, $\delta$ is the (sub-)grain size or cell size in the unrecrystallised part of the material, $\alpha_{2}$ is a constant (typically equalling 2 [44]) and $D$ is the grain size of the recrystallised part of the material. The approximation indicated is valid because $D>>\delta$. TEM work on $7 \mathrm{xxx}$ alloys with $\mathrm{Zr}$ additions has shown $[45,46]$ that $\delta$ is about $1.5 \mu \mathrm{m}$ when the alloys were hot rolled using procedures similar to industrial practice.

$M$ depends on the texture and the orientation of the tensile axis, the definition of the orientation angles $\phi$ and $\varphi$ for a rolled plate are shown in Fig. 2. Several models are available to determine $M(\varphi, \phi)$. The lower bound solution for $M(\varphi, \phi)$ is obtained from the Sachs model [19], which assumes one slip system is active, and the upper bound solution is obtained from the Taylor model [20], which assumes 5 slip systems are active. For texture free FCC metals the Taylor model predicts $M_{T}=3.07$ [47]. Neither of these two models is realistic for polycrystals. Self-consistent models, like the one due to Hutchinson [21], indicate that on average about 3.5 slip systems are active. For equiaxed grains in texture free FCC metals Hutchinson's model gives $M \cong 2.6$ [22]. In the present model we will apply these results from self-consistent models and estimate $M$ for alloys by taking the average of the cases where 3 and 4 systems are active. This is considered to be a good approximation, provided texture is not so intense as to virtually produce a material with only one or two grain orientations. (This procedure thus assumes that the number of slip systems that are active is not influenced significantly by typical rolling textures, or aspect ratios of grains. $M(\varphi, \phi)$ is calculated by determining, for each grain, $i$, the values of the Schmid factor, $m_{i j}$, for the 12 directions, $j$, of the $\{111\}<110>$ slip systems in the FCC structure. The Schmid factors are ordered such that $m_{i 1}>m_{i 2}>m_{i 3}$ etc. The average $M$ is calculated from 


$$
M(\varphi, \phi)=\sum_{i} \frac{f_{i} j_{\max }}{\sum_{j=1}^{j_{\max }} m_{i j}}
$$

Where $f_{i}$ is the volume fraction of grain, $j$ represents the activated slip systems, with $j_{\max }$ the maximum number of activated slip systems $\left(j_{\max }=1\right.$ for the Sachs model and $j_{\max }=5$ for the Taylor model).

It is important to note that following this analysis, recrystallisation reduces the yield strength for loading in the rolling direction by two mechanisms. Firstly, recrystallisation weakens the alloy by reducing the number of (sub-) grain boundaries. And, secondly, recrystallisation reduces the occurrence of rolling textures, which tend to have higher $M\left(\varphi=0^{\circ}, \phi^{\circ} 0^{\circ}\right)$ ( $M$ in the rolling direction), as compared to random textures and recrystallisation textures [6] (see Table 2). For typical rolling textures, $M\left(\varphi=0^{\circ}, \phi=0^{\circ}\right)$ values are about $15 \%$ larger as compared to $M\left(\varphi=0^{\circ}, \phi=0^{\circ}\right)$ for recrystallisation textures (Table 2). Thus we can expect that alloys that contain more effective recrystallisation inhibitors, would be stronger in the rolling direction. For 7xxx alloys the $\mathrm{Zr}$ containing alloys would be expected to be stronger than $\mathrm{Cr}$ containing variants. (Also elongated grains will have some influence on strength anisotropy, however, this effect is limited [6], and will not be considered.)

\section{$4 \quad$ Results and Analysis}

\subsection{Microstructure and microstructure development}

For the present work a selection of the Cr containing and $\mathrm{Zr}$ containing alloys that are part of the yield strength database were investigated by DSC, TEM and SEM. The TEM observations revealed that the aged alloys contain a dense and largely homogeneous distribution of precipitates, which are predominantly $\eta$ precipitates $[13,28]$. The DSC data for the Al-6.1Zn-2.3Mg-2.6Cu-0.1Zr alloy is presented in Fig. 3. In the temperature range up to $400^{\circ} \mathrm{C}$, the DSC curves show 3 main effects, marked II-IV. (Since all alloys were in the overaged condition, formation of GP zones (effect I) and dissolution of GP zones and most of the precipitation of $\eta^{\prime}$ have been completed prior to DSC experiments and thus these reactions are not observed.) In earlier work by us [13] and by other authors [48] it was suggested that effect II is mainly caused by the dissolution of $\eta^{\prime}$, with effect III corresponding to the formation of $\eta$, either through precipitation of $\mathrm{Zn}$ and $\mathrm{Mg}$ or through transformation of $\eta^{\prime}$, and effect IV being due to the dissolution of $\eta$. However, even though identification of SAD patters has proved controversial [28], most recent work indicates that at peak ageing condition little $\eta^{\prime}$ is left [53] and that on overageing $\eta$ is the only hardening phase present. Hence, even though $\eta^{\prime}$ dissolution might contribute to Effect II in the sample aged $2 \mathrm{~h}$ at $172^{\circ} \mathrm{C}$, this 
reaction cannot explain the continued presence of Effect II after longer ageing times. In fact, it is possible that effects II-IV are mainly due to reactions involving only $\eta$ precipitates, with initial dissolution of small precipitates, coarsening (possibly with reprecipitation), and finally, dissolution of the larger, coarsened precipitates defining Effects II, III and IV. In fact, the position of Effect III with peak at about $265-280^{\circ} \mathrm{C}$, is consistent with predictions of the kinetics of heat release due to the coarsening reaction (see Appendix). If we consider Effect II to be an exothermic effect superimposed on a broader endotherm from about 170 to about $460^{\circ} \mathrm{C}$, the estimated magnitude is about 10 to $15 \%$ of the total endotherm. This appears to be a reasonable magnitude for the coarsening reaction. In view of this it is believed that Effects II, III and IV are dominated by dissolution of small $\eta$ precipitates, coarsening/reprecipitation and finally, dissolution of $\eta$ precipitates.

In alloys with high $\mathrm{Cu}$ content, two further effects are observed in the temperature range 400$475^{\circ} \mathrm{C}$. These two effects are thought to be due to the formation and subsequent dissolution of $\mathrm{S}$ phase [13]. The melting of undissolved $\mathrm{S}$ and $\mathrm{T}$ phase, which occurs in the range 475 to $500^{\circ} \mathrm{C}$ has been discussed elsewhere [16].

In assessing the relation between microstructure and strength, especially effects II and III are important, as these effects are directly related to the amount and sizes of strengthening precipitates present in the alloy. The absence exothermal peak due to the formation of $\eta^{\prime}$ and $\eta$ DSC curves of alloys aged at $170^{\circ} \mathrm{C}$ shows that precipitation in our alloys (which are all peak aged or overaged) is largely complete and that the alloys are thus in the early stages coarsening.

\section{2 $\quad$ Texture and $M$ factor}

The EBSD work was carried out on $8 \mathrm{Zr}$-containing and $4 \mathrm{Cr}$-containing alloys that are part of the yield strength database. Fig. 4 and Fig. 5 show typical grain boundary maps from a Zr- and a Crcontaining alloy, respectively. These figures reveal that many grains contain subgrains of sizes in the order of one to several micrometers, whilst others are entirely free of subgrains. The subgrain containing grains are considered to be unrecrystallised grains. As has been demonstrated in various previous investigations, the unrecystallised and recrystallised regions form bands oriented in the rolling direction. Comparison of Fig. 4 and Fig. 5 shows that the $\mathrm{Cr}$ containing alloy has a higher fraction of recrystallisation, and the observation was confirmed for other alloys studied by EBSD. On average, Zr containing alloys are about 39\% recrystallised, whilst the Cr-containing alloy is about $65 \%$ recrystallised. The predominant texture components for the $\mathrm{Zr}$ containing alloys were the S, brass and Goss textures, which are known to be rolling textures [47]. For the Cr containing alloys, these three textures were considerably reduced, and the cube texture (which is generally considered to be the main recrystallisation texture [47]) was considerably increased. For 15 alloys, grain structures were studied by optical microscopy. These observations were consistent with the 
EBSD observations, and did not reveal any strong variations in grain structure between alloys within one of the two groups of alloys [49].

Fig. 6 shows $M(\varphi=0, \phi)$ vs. $\phi$ for the Zr-containing alloy Al-6.7Zn-2Mg-1.9Cu-0.1Zr, as obtained from the method outlined in section 3.6. The results show that Taylor factor ( $M$ for 5 activated slip systems) can be very high, especially around $M\left(\varphi=0, \phi=90^{\circ}\right)$, i.e. short transverse direction, which means certain $m$ in the $5^{\text {th }}$ slip system are very low and can not be expected to be activated. As indicated in section 3.6, we will follow results from self-consistent models and calculate $M$ as the average of the cases where 3 and 4 slip systems are activated. The results for the effective $M$ of $\mathrm{Zr}$ containing alloys, $M_{Z r}$, and $M$ for Cr-containing alloys, $M_{C r}$, are shown in Fig. 7 and Fig. 8. The figures reveal variations in $M(\varphi=0, \phi)$ vs. $\phi$ and between the different alloys, but all variations are comprised within $2.7 \pm 0.22$. As expected for the present alloys that contain substantial texture, $M$ varies with orientation. The average trends of $M(\varphi=0, \phi)$ for the $\mathrm{Zr}$ containing alloys (Fig. 7) are consistent with literature data on yield strength anisotropy in rolled $\mathrm{Zr}$ containing alloys, which show that yield strength at $\phi=0^{\circ}$ is considerably higher than that at $\phi=90^{\circ}$ with a local maximum in yield strength at about $60^{\circ}$ [6]. Similar plots for $M(\varphi, \phi=0)$ vs. $\varphi$ reveal much more limited variations in $M$ (figures not presented).

For selected samples, the $M$ factors for recrystallised and unrecrystallised areas were analysed, and in line with other work it was found that textures were very different between the two types of areas and in general $M\left(\varphi=0^{\circ}, \phi=0^{\circ}\right)$ values are lower for the recrystallised areas. Thus differences between $M_{C r}\left(\varphi=0^{\circ}, \phi=0^{\circ}\right)$ and $M_{Z r}\left(\varphi=0^{\circ}, \phi=0^{\circ}\right)$ can be expected as $\mathrm{Zr}$ additions are more effective in reducing recystallisation than $\mathrm{Cr}$ additions, which causes a different average texture between the two classes of alloys. Although at some orientations differences are not statistically significant, differences do appear to be significant when $M_{Z r}>2.7$, i.e. at $\varphi$ between $0^{\circ}$ and $10^{\circ}$ and between $40^{\circ}$ and $70^{\circ}$. Our yield strength database contains data on yield strength for loading in the rolling direction and in that direction $M_{C r}\left(\varphi=0^{\circ}, \phi=0^{\circ}\right)=2.66$, and $M_{Z r}\left(\varphi=0^{\circ}, \phi=0^{\circ}\right)=2.73$. No statistically significant relation between $M$ values and content of main alloying elements $\mathrm{Zn}, \mathrm{Mg}$ or $\mathrm{Cu}$ was detected. The differences in $M$ values between alloys within one of the two classes are thought to be mainly due to statistical variations resulting from the limited number of bands of recrystallised grains studied, and, possibly, to small differences in recrystallisation due to unintended, small variations in rolling conditions.

\subsection{Strength modelling}

To model the yield strengths of the 21 alloys first those parameters that are either well known or known to a sufficient accuracy were identified. $\Delta Q_{S}$ was taken to be equal to the enthalpy of solution of $\eta$ phase, which was determined (in [28]) by fitting a regular solution model to data obtained from thermodynamic modelling [26]. $T_{S}$ was determined by considering that an Al-6.1Zn- 
$2.35 \mathrm{Mg}-0.1 \mathrm{Zr}$ alloy aged $10 \mathrm{~h}$ at $160^{\circ} \mathrm{C}$ contains a volume fraction of precipitates of about $4.3 \%$. This yields $T_{S}=285^{\circ} \mathrm{C}$. The activation energy for the coarsening reaction driving the microstructural changes was taken from an analysis of coarsening in a 7050 alloy by Dorward [50]: $Q_{A}=135 \mathrm{~kJ} /$ mole. As dissolved impurities and minor alloying elements such as $\mathrm{Fe}, \mathrm{Si}, \mathrm{Mn}, \mathrm{Cr}$ and $\mathrm{Zr}$ will contribute a small amount of solution strengthening we will take $\tau_{o}$ as the CRSS of annealed $1060 \mathrm{Al}$, which is about 7MPa. The coefficient for solution strengthening was determined by using the data by Dorward [50], which showed that on ageing an Al-6.45wt\%Zn-2.10wt\%Mg$2.15 \mathrm{wt} \% \mathrm{Cu}-0.10 \mathrm{wt} \% \mathrm{Zr}-0.07 \mathrm{wt} \% \mathrm{Fe}$ alloy for very long times, the yields strength converges to $130 \mathrm{MPa}$. This allows $C_{2}$ to be fixed by considering prediction in the limit of $t \rightarrow \infty$. For the present peak and overaged alloys, $n$ and $\eta_{i}$ have little effect on model predictions, and we chose values characteristic for precipitation in a range of Al alloys: $n=1 \frac{1 / 2}{2}$ and $\eta_{i}=2$ [51,52]. In the present model $k_{o}$ determines to a large extent the time to peak strength during ageing. We were thus able to determine the value of $k_{o}$ by adjusting it through trial and error such that the measured time to peak strength in an $\mathrm{Al}-6.1 \mathrm{Zn}-2.3 \mathrm{Mg}-0.1 \mathrm{Zr}$ and a 7010 alloy corresponds with model predictions (predicted $5 \mathrm{~h}$ at $160^{\circ} \mathrm{C}$, measured about $6 \mathrm{~h}$ at $160^{\circ} \mathrm{C}$ for 7010 and $4 \mathrm{~h}$ for $6.1 \mathrm{Zn}-2.3 \mathrm{Mg}-0.1 \mathrm{Zr}$ [6]). $C_{S, R}$ was taken as the $C_{s}$ value for the reference alloy $(\mathrm{Al}-6 \mathrm{wt} \% \mathrm{Zn}-2.3 \mathrm{wt} \% \mathrm{Mg}-3 \mathrm{wt} \% \mathrm{Cu})$. Tomographic atom probe and TEM work indicates that at near peak age condition the thickness of disc shaped precipitates is mostly between about 2 to $3 \mathrm{~nm}$ and the aspect ratio is about 2.5 to 4 , with sometimes also more globular particles appearing [34,53,54,55]. TEM work on aged AA7108 shows similar aspect ratios [56]. Hence we took $l_{t, o}=2.5 \mathrm{~nm}$ and $l_{D} / l_{t}=3$.

Eq. 26 is valid for strengthening due to disc shaped precipitates of uniform size and thus there are uncertainties related to evaluation of $\Delta \tau_{p p t}$ in the present alloys because i) precipitates are nearer ellipsoidal than disc shaped, ii) precipitates have a range of sizes, and appropriate average values of $l_{t, o}$ and $f_{o}$ are difficult to determine accurately, iii) hampering of dislocation movement due to the strain field near the precipitates may occur, which would increase precipitate strengthening. Due to these uncertainties we will allow one single fittable parameter in the determination of $\Delta \tau_{p p t}$, and hence we will take:

$$
\Delta \tau_{\text {prec }}=C_{4} \frac{G b}{\left(l_{D} l_{t}\right)^{1 / 2}}\left[f^{1 / 2}+0.70\left(\frac{l_{D}}{l_{t}}\right)^{1 / 2} f+0.12\left(\frac{l_{D}}{l_{t}}\right) f^{3 / 2}\right]
$$

In order evaluate the model and test its accuracy in an objective way we used train and test methods developed originally in the context of adaptive numeric modelling [33,57]. Thus, training and testing was performed by repeatedly splitting the available data in sets for training and testing (about $\sim 50 \%$ training data and $\sim 50 \%$ test data), and the root of the mean squared error (RMSE) in prediction on the test data ('unseen' data) represents the accuracy of the model. Thus the RMSE(test) values reported below are from true independent tests of the model: the model and fitted parameters in it are in no way derived from the data with which it is tested. 
After some extensive verification of the stability of the model predictions with respect to small variations in the parameters outlined above, two attempts at fitting the remaining model parameters were made. Firstly, we selected $B_{C u}=B_{M g}=1$ and fitted $k_{o, c}$ and $C_{4}$. This yielded a good fit with $\operatorname{RMSE}($ test $)=14.1 \mathrm{MPa}$. Secondly, we fitted all four parameters $\left(B_{C u}, B_{M g}, k_{o, c}\right.$ and $\left.C_{4}\right)$, which yielded very similar fits, now with RMSE(test) $=13.8 \mathrm{MPa}$. The small difference suggests that our initial estimate $B_{C u}=B_{M g}=1$ is reasonable. To verify that all fixed parameters were reasonable, further model optimisation was attempted by allowing up to 10 model parameters to be fitted. This did not produce an improvement in RMSE(test), and thus the parameters obtained from the assessment of microstructural data and the literature are sufficiently accurate.

A prediction-scatter plot (plot of measured vs predicted yield strengths) for all 7xxx alloys shows all groups of alloys have broadly similar modelling accuracy and accuracy does not depend significantly on alloy strength (plots not included). Fig. 9 shows predicted and measured strengths (for $B_{C u}=B_{M g}=1$ ) as a function of $x_{Z n}+x_{M g}+x_{C u}$, for alloys that have a range of predicted volume fractions of precipitates. The strength prediction deviates from the root square of volume fraction behaviour, predicted by classical precipitate bypassing models. Fig. 10 shows predicted and measured proof strengths for three alloys that have very similar predicted volume fractions of precipitates.

\section{$5 \quad$ Discussion}

To critically evaluate the relative value of the accuracies achieved with the present model we will consider the inherent accuracy of the data in the database, compare the present approach with other modelling approaches and consider whether the fitted model parameters are physically reasonable. We will first consider the accuracy of the data.

Analysis of the duplicate tests on samples that were machined from the same thermo-mechanically treated plate indicated that the yield strength data is accurate within $3 \mathrm{MPa}$. This indicates that both the variations in strength between neighbouring locations in a single plate and possible inaccuracies in single yield strength measurements can not be a factor in the modelling accuracy $(\mathrm{RMSE}=14 \mathrm{MPa})$. Instead, the main sources of variations and modelling inaccuracies are thought to result from variations and inaccuracies in the input parameters of the model, especially in $M$ and to a lesser extent in the compositions and temperatures for heat treatment. To analyse this, we determined how variations in input parameters, that are typical of measured variations or typical measurement accuracies, influence the resulting yield strength predictions. This shows that a variation in $\mathrm{Mg}$ content of $0.05 \mathrm{wt} \%$ produces a deviation in $\sigma_{y}$ of about 2 to $3 \mathrm{MPa}$, a variation in ageing temperature of $0.5^{\circ} \mathrm{C}$ produces a deviation in $\sigma_{y}$ of $3 \mathrm{MPa}$ for significantly overaged alloys 
and, more importantly, a variation in $M$ of 0.07 (which is about the variation seen between alloys in Fig. 7 and Fig. 8) produces a deviation in $\sigma_{y}$ of about $12 \mathrm{MPa}$. If these deviations are independent they should be added quadratically, and thus they can explain the accuracy limit of the model. In relation to the strength of commercial Al based alloys, this assessment thus indicates that after accounting for relatively easily accessible parameters such as average plate compositions, heat treatment temperatures and average $M$ factors of nominally identical alloys, variations in the strength due to other, less accessible sources such as (local) $M$ factor and microsegregation will occur. This view is supported by results of analysis of large databases on yield strengths and processing parameters of nominally identical Al based alloys using adaptive numeric modelling (ANM) which show residual RMSE(test) values of about $1.5 \%$ for $\sigma_{y}$ determined for commercially produced 2024-T351 (Al-Cu-Mg-Mn) [57], similar to the residual deviations of the present model. A further observation supporting this interpretation of the source of deviations is that for the majority of the alloys investigated predicted values were either all higher or all lower than the measured ones.

To further evaluate the relative achievements of the model, ANM approaches were applied to the data set and subsections of the data set $[58,59]$. We will here refer to ANM using the highly flexible and potentially very accurate SUpport vector Parsimonious ANalysis Of VAriance (SUPANOVA) approach [60]. When applied to 36 alloy/ageing combinations for 9 Zr-containing alloys, RMSE(test) achieved was about $29 \mathrm{MPa}$ [58]. When adaptive numeric models are presented with more data accuracy should improve, and this was confirmed by using a more extensive set of 71 alloy/ageing combinations for Zr-containing alloys for which the RMSE(test) was about $22 \mathrm{MPa}$ [59]. If it would be possible to continue (exponentially) increasing the amount of data available for ANM analysis, numerical modelling theory indicates that the ANM approach should be able to match the accuracy of the present physically based model. However, as is often observed in industrially driven research, this data was not available and obtaining the data would be impractical due to the cost of alloy production, processing and testing. Thus, in the context of these realistic limitations, the present physically based model performs better than these adaptive numeric models. And, perhaps more importantly, it provides a direct insight into the processing-microstructurestrength relations. (But, adaptive numeric modelling approaches have its own advantages, i.e. they are more 'flexible' in dealing with large and complex data sets where prior physical understanding is very limited [57].)

In the present model two parameters are fitted: $k_{o, c}$ and $C_{4}$. For the model to be physically sound these fitted parameters must be related to physical quantities. As $k_{o, c}$ is the main factor determining the size of precipitates in the coarsening stage, we compared the predicted $l_{D}$ with the effective diameter of precipitates on TEM micrographs of overaged $\mathrm{Al}-\mathrm{Zn}-\mathrm{Mg}-\mathrm{Cu}$ based alloys. Here it is important to note that for a dispersion of particles with varying sizes, the effective size for strengthening is not equal to the average size of the particles, but is in fact considerably greater. 
This can be shown by dividing the particle size distribution up in $i$ bins, each bin having $N_{i}$ particles of average size $l_{i}$. The contribution to dispersion strengthening of particles in each bin is proportional to $f_{i}^{\kappa} / l_{i}$, where $f_{i}$ is the volume fraction of particles in bin $I$ and $\kappa$ is a constant. (For small volume fractions $\kappa$ equals 0.5 , but for our case with substantial volume fractions of disc shaped precipitates $\kappa$ equals about 0.58.) Work on superposition of strengthening effects (see [5] and references therein) indicates that in this case the superposition of these strengthening effects can be approximated as:

$$
\Delta \tau_{\text {all }}=C_{6}\left[\sum\left(\frac{f_{i}{ }^{\kappa}}{l_{i}}\right)^{2}\right]^{1 / 2}=C_{7}\left[\sum\left(N_{i}{ }^{\kappa} l_{i}{ }^{3 \kappa}\right)^{2} l_{i}{ }^{-2}\right]^{1 / 2}
$$

So, essentially, the effective value for $1 / l^{2}$ is obtained by a weighted average of $1 / l_{i}^{2}$ with weighting factors $\left(N_{i}{ }^{\kappa} l_{i}{ }^{3 \kappa}\right)^{2}$. We applied this analysis to obtain effective $1 / l_{D}{ }^{2}$ values from a number of TEM micrographs obtained both from our alloys and work on other $\mathrm{Al}-\mathrm{Zn}-\mathrm{Mg}(\mathrm{Cu})$ alloys published in the literature. (As foil thickness will have a small but noticeable influence on the distribution of particle sizes, we corrected for foil thickness effects by assuming particles were disc shaped and very thin and foil thickness was assumed to be 100nm.) Results presented in Table 3 show a very good correspondence between measured effective diameters and predicted diameters. Thus the value of $k_{o, c}$ used in the model is realistic. In retrospect, this result shows that we could have elected to use the measured effective diameters to determine $k_{o, c}$ and obtain a model with equivalent accuracy by fitting just one parameter $\left(C_{4}\right)$. As the present model avoids making direct predictions of $\Delta \tau_{p p t}, C_{4}$ (the precipitate by-passing effect factor) cannot be related directly to a physical quantity that is accessible from microstructure analysis. However, it has been shown by other authors that in overaged Al-Zn-Mg(-Cu) alloys precipitates sizes follow an LSW type coarsening law $[3,50]$ and that strength of an $\mathrm{Al}-\mathrm{Zn}-\mathrm{Mg}(-\mathrm{Cu})$ alloy can be related directly to size of particles via classical dispersion strengthening theory [3]. This indicates that also this part of the model is likely to be physically sound, and the $C_{4}$ determined should be physically reasonable.

From a modelling point of view, it can be beneficial to be able to estimate $M$ factors from recrystallisation fraction, $f_{\text {ReX }}$, without measuring textures, as this would allow incorporation of recrystallisation models into the present model. If rolling yields consistent textures and recrystallisation yields a different consistent type of texture, $M$ factors would be given by a rule of mixtures:

$$
M(\phi, \varphi)=\left(1-f_{\operatorname{Re} X}\right) M_{r o l l}(\phi, \varphi)+f_{\operatorname{Re} X} M_{\operatorname{Re} X}(\phi, \varphi)
$$

where $M_{\text {roll }}$ is the $M$ factor for rolling texture and $M_{R e X}$ is the $M$ factor for a recrystallisation texture. Our determinations of $M\left(\varphi=0^{\circ}, \phi=0^{\circ}\right)$ and recrystallisation fractions suggest that 
$M_{\text {roll }}\left(\varphi=0^{\circ}, \phi=0^{\circ}\right) \cong 2.8$ and $M_{R e X}\left(\varphi=0^{\circ}, \phi=0^{\circ}\right) \cong 2.55$, and these values are broadly in line rolling textures to be a mixture of the known rolling textures $\mathrm{Cu}$, Brass, $\mathrm{S}$ and Goss with limited random components and recrystallisation textures being mostly random, with some cube components (Lebensohn et al. [61] considered similar recrystallisation components).

When allowed to be fitted to the data, we found $B_{C u}=1.7$ and $B_{M g}=1.2$, which indicates that (when expressed in atomic fractions) the strengthening effect of $\mathrm{Mg}$ is almost similar to that of $\mathrm{Zn}$, and that strengthening due to $\mathrm{Cu}$ is more significant (note that when expressed in $\mathrm{wt} \%$, variations in $\mathrm{Mg}$ content will have the strongest influence). This result appears to be different from assessments of strength data of 7xxx alloys using ANM models, which suggested that Mg has a stronger effect than $\mathrm{Cu}[33,58]$. These ANM models did not include terms that represent an influence of alloying content on ageing rate. Conversely, the present model predicts that $\mathrm{Zn}, \mathrm{Mg}$ and $\mathrm{Cu}$ content all influence ageing rate through $K_{r e l}$ and $k$ and the present model predicts that variations in $K_{r e l}$ cause differences in yield strength of upto about $3 \mathrm{MPa}$. Clearly, this is very small compared to both the major influences on the strength as well as the variations in the strength due to less accessible sources such as (local) $M$ factor and microsegregation. Thus, it is clear that ANM modelling was unable to detect evidence of these binary and higher order interactions due to inherent limitations of the dataset (limited size, variability in input parameters) in combination with a relatively small influence on yield strength. However, when applied to electrical conductivity data, which is very sensitive to both precipitate coarsening and $\mathrm{Mg}$ dissolved in the Al-rich phase, but less sensitive to $\mathrm{Zn}$ and $\mathrm{Cu}$ dissolved, these ANM models included binary terms combining ageing time and $\mathrm{Mg}$ content $[33,58]$. Thus the ANM analysis in Refs. $[33,58]$ is consistent with the present model and provides evidence, independent of any physically based models or presumptions, that content of at least one alloying element does influence coarsening rate.

Although the model is quite accurate, a few limitations should also be discussed. Firstly, it is noted that for rolled 7xxx alloys the difference between longitudinal and long-transverse yield strength varies during ageing: for underaged alloys the longitudinal yield strength is substantially higher, and for overaged alloys the difference is reduced for the Zr containing 7010 alloy [6] and reversed for the $\mathrm{Cr}$ containing 7475 [62]. Texture will not change on ageing, and apparently precipitation of precipitates with preferential orientations in conjunction with (relaxation of) residual stresses combine to produce an anisotropy in yield stress that is stronger and opposite to the effects of texture $[6,62]$. The present model disregards the influence of these ageing time dependent processes on yield strength anisotropy, for which little data is available, and assumes this anisotropy is only influenced by crystallographic texture. Also stretching prior to ageing influences yield strength in a multitude of ways, changing ageing rate, maximum strength and anisotropy, and these effects are not included in the model. Further, coarsening rates depend on matrix-precipitate interfacial energies, which can depend on temperature, matrix composition, precipitate composition and 
precipitate-matrix coherency. The model neglects these possible influences on interfacial energies mainly because they are presumed to be small and certainly difficult to verify.

In conclusion, regardless of the kind of assumptions made, or which type of mechanisms are adopted in the present model, the model can predict unseen data very well, it can extrapolate well, residual errors can be explained as being due to small variations (especially in local texture) inherent to the alloy plate production process and all parameters can be explained on the basis of microstructural data. This model, in conjunction with the conductivity model presented elsewhere [28], can provide a useful tool for predicting the properties of a wide range of peak and overaged $7 \mathrm{xxx} \mathrm{Al}$ alloys and hence it is also valuable for commercial use, providing the effects of stretching and two stage ageing can be included. The present model further differs from many other recent modelling approaches in that it uses straightforward mathematical equations and avoids implicit equations or iterative schemes. This allows rapid inverse predictions, e.g. prediction of the compositions and heat treatments needed to obtain specified yield strengths and plotting of iso-yield strength curves. As an example of this we calculated the ageing time at various temperatures required to obtain a yield strength of $500 \mathrm{MPa}$ in the rolling direction as a function of the sum of atomic percentage $\mathrm{Zn}, \mathrm{Mg}$ and $\mathrm{Cu}$ alloy content for alloys with $\mathrm{Zn}: \mathrm{Mg}: \mathrm{Cu}$ contents of ratio 2.5:2:0.7 and 39\% recystallisation Fig. 11.

On a more general note, the present modelling exercise shows that by employing different components of models that were in most cases derived and verified for simpler alloys systems and by superimposing individual strengthening contributions, the present physically-based modelling approaches can predict the composition and processing dependency of yield strength in complex age hardening Al based alloys. This shows that when combined with models that deal with additional aspects of strength of precipitation-hardened alloys, such as (dynamic) recrystallisation, complete physically-based models for strengthening of highly complex alloys can be constructed.

\section{Conclusions}

A model for the yield strength of multicomponent alloys is presented. It is based on an approximation of the increase in CRSS of grains due to precipitate by-passing during precipitate coarsening and takes account of ternary and higher order systems. Also more subtle effects such as the influence of supersaturation on precipitation rates and of volume fraction on coarsening rates, as well crystallographic texture and recystallisation are taken into account. $M$ factors were determined by EBSD.

The model has been used to fit and predict the proof strength data of a database containing data on $21 \mathrm{Al}-\mathrm{Zn}-\mathrm{Mg}-\mathrm{Cu}$ alloys, with compositions spread over the whole range of commercial alloying compositions. The alloys were aged for a range of times and temperatures to produce yield 
strengths ranging from 400 to $600 \mathrm{MPa}$. All but one of the microstructural and reaction rate parameters in the model are determined on the basis of microstructural data, with one parameter fitted to yield strength data. The resulting accuracy in predicting unseen proof strength data is 14 $\mathrm{MPa}$. In these alloys precipitation hardening is the main strengthening component, and coarsening of precipitates and the maximum attainable volume fraction of precipitates are the main factors determining the difference in strength. The model indicates that, in terms of atomic fraction, $\mathrm{Zn}$ and $\mathrm{Mg}$ are equally effective in strengthening the Al- $\mathrm{Zn}-\mathrm{Mg}-\mathrm{Cu}$ alloys. To verify the physical basis of the model, microstructures and phase transformations of 7xxx alloys were studied by DSC, EBSD and FEG-SEM, and published TEM work was analysed. All this work is consistent with the model and it is especially shown that recrystallisation, which is influenced by $\mathrm{Zr}$ and $\mathrm{Cr}$ additions, has a distinct influence on the yield strength in the rolling direction.

In general, physically-based modelling approaches, such as the one presented in this paper, can predict the composition and processing dependency of yield strength in complex age hardening Al based alloys.

\section{Acknowledgements}

The authors would like to acknowledge British Aluminium Plate (currently Alcoa Europe - Flat Rolled Products, Birmingham, UK) for providing the database and selected alloys. The alloy plates were produced at QinetiQ (formerly DERA), Farnborough, UK. Dr. X.M. Li is acknowledged for performing DSC experiments, data collection and performing initial modelling attempts.

\section{Appendix}

For thermally activated reactions for which the temperature dependency can be described well by a single Arrhenius term, the time, $t_{e q}$, for obtaining an state of the reaction during isothermal ageing that is equivalent to the state obtained by linear heating to a temperature $T_{f}$, can be determined through approximating the so-called temperature integral (or Arrhenius integral). Using the socalled Murray and White approximation [63] it is found that [64]:

$$
t_{e q} \cong \frac{T_{f}}{\beta} \frac{R T_{f}}{E} \frac{\exp \left(-\frac{E}{R T_{f}}\right)}{\exp \left(-\frac{E}{R T_{\text {iso }}}\right)}
$$

and a somewhat better accuracy is obtained by employing the approach in [63] which leads to: 


$$
t_{\text {eq }} \cong 0.786 \frac{T_{f}}{\beta}\left(\frac{R T_{f}}{E}\right)^{0.95} \frac{\exp \left(-\frac{E}{R T_{f}}\right)}{\exp \left(-\frac{E}{R T_{\text {iso }}}\right)}
$$

where $t_{e q}$ is the isothermal ageing time at temperature $T_{i s o}, T_{f}$ is the temperature reached during heating at constant rate $\beta$, and $E$ is the activation energy for the reaction.

The present model indicates that during ageing at $172^{\circ} \mathrm{C}$ precipitation is complete in about $1 \mathrm{~h}$ and that on ageing for an additional $3.5 \mathrm{~h}$ the particles size increases by a factor $\sqrt{2}$, i.e. in that $3.5 \mathrm{~h}$ the total surface area of the particles is halved, and consequently the total interfacial energy in the system is also halved. After ageing for $2 \mathrm{~h}$ at $172^{\circ} \mathrm{C}$ some coarsening has occurred and a further halving of the surface area will then take $5 \mathrm{~h}$, and after ageing $8 \mathrm{~h}$ at $172^{\circ} \mathrm{C}$ substantial coarsening has occurred and a further halving of the surface area will occur on an additional $15 \mathrm{~h}$ ageing. Applying either of the latter two equations, with $E=135 \mathrm{~kJ} / \mathrm{mol}$ (see section 4.3 ), we then find that $50 \%$ completion of the coarsening heat effect during DSC heating at $10^{\circ} \mathrm{C} / \mathrm{min}$ should occur at $246^{\circ} \mathrm{C}$ for an alloy that was aged for $2 \mathrm{~h}$ at $172^{\circ} \mathrm{C}$ and at $264^{\circ} \mathrm{C}$ for an alloy aged for $8 \mathrm{~h}$ at $172^{\circ} \mathrm{C}$. These predictions are consistent with the position of effect III in Fig. 3 and its shift on increased isothermal ageing, thus supporting the interpretation that this effect is mainly due to coarsening. 


\section{Tables}

Table 1 Compositions of alloys referred to in this work. (wt\%)

\begin{tabular}{|l|l|l|l|l|l|l|l|l|l|}
\hline Alloy & $\mathrm{Zn}$ & $\mathrm{Mg}$ & $\mathrm{Cu}$ & $\mathrm{Zr}$ & $\mathrm{Cr}$ & $\mathrm{Ti}$ & $\mathrm{Mn}$ & $\mathrm{Fe}$ & $\mathrm{Si}$ \\
\hline 7010 & $5.7-6.7$ & $2.1-2.6$ & $1.5-2.0$ & $0.10-0.16$ & $<0.05$ & $<0.06$ & $<0.10$ & $<0.15$ & $<0.12$ \\
\hline 7040 & $5.7-6.7$ & $1.7-2.4$ & $1.5-2.3$ & $0.05-0.12$ & $<0.04$ & $<0.06$ & $<0.04$ & $<0.13$ & $<0.10$ \\
\hline 7050 & $5.7-6.7$ & $1.9-2.6$ & $2.0-2.6$ & $0.10-0.15$ & $<0.04$ & $<0.06$ & $<0.10$ & $<0.15$ & $<0.12$ \\
\hline 7150 & $5.9-6.9$ & $2.0-2.7$ & $1.9-2.5$ & $0.08-0.15$ & $<0.04$ & $<0.06$ & $<0.10$ & $<0.15$ & $<0.12$ \\
\hline 7075 & $5.1-6.1$ & $2.1-2.9$ & $1.2-2.0$ & $<0.05$ & $0.18-0.28$ & $<0.2$ & $<0.3$ & $<0.5$ & $<0.4$ \\
\hline 7475 & $5.2-6.2$ & $1.9-2.6$ & $1.2-1.9$ & $<0.05$ & $0.18-0.25$ & $<0.06$ & $<0.06$ & $<0.12$ & $<0.10$ \\
\hline 7449 & $7.5-8.7$ & $1.8-2.7$ & $1.4-2.1$ & $* \wedge$ & $<0.05$ & $*$ & $<0.2$ & $<0.15$ & $<0.10$ \\
\hline
\end{tabular}

$* \mathrm{Ti}+\mathrm{Zr}<0.25$

$\wedge \mathrm{Zr}$ content of 7449 is typically about $0.1 \mathrm{wt} \%$

Table $2 M$ values for macroscopic loading in the rolling direction for various rolling and recrystallisation textures, and 1 to 5 activated slip systems.

\begin{tabular}{|c|c|c|c|c|c|}
\hline 5 systems & 4 systems & 3 systems & 2 systems & 1 system & 3.5 systems \\
\hline model) & & & & model) & self-consistent model) \\
\hline
\end{tabular}

Typical Rolling textures

$\begin{array}{lllllll}\text { C } & 3.70 & 3.52 & 3.36 & 3.04 & 3.04 & 3.44 \\ \text { S } & 3.33 & 3.08 & 2.85 & 2.63 & 2.50 & 2.97 \\ \text { B } & 3.17 & 3.04 & 2.84 & 2.44 & 2.44 & 2.94\end{array}$

Rolling/recrystallisation texture

Goss

2.45

2.45

2.45

2.45

2.45

2.45

Typical recrystallisation texture

Cube
CubeRD
CubeND
R
P
Q

2.45

2.45

2.45

2.45

2.45

2.45

2.45

2.45

2.45

2.45

2.45

2.45

2.85

2.72

2.49

2.03

2.60

3.01

2.72

2.57

2.38

2.03

2.65

3.97

3.60

3.29

2.11

3.45

3.16

2.84

2.46

2.68

2.65

Texture free FCC 
Table 3 Effective diameters of precipitates (see text) otained from analysis of published TEM micrographs and predicted diameters of the disc shaped precipitates in overaged Al-Zn$\mathrm{Mg}(-\mathrm{Cu})$ alloys. Typical accuracy of determined effective diameter is about $15 \%$, except where indicated.

\begin{tabular}{|l|c|c|c|c|}
\hline Alloy & $\begin{array}{c}\text { Ageing } \\
\text { treatment }\end{array}$ & $\begin{array}{c}\text { Diameter } \\
\text { Measure } \\
d \\
(\mathrm{~nm})\end{array}$ & $\begin{array}{c}\text { Diameter } \\
\text { Predicted } \\
(\mathrm{nm})\end{array}$ & Ref. \\
\hline Al-6.1Zn-2.35Mg-0.1Zr & $50 \mathrm{~h} / 160^{\circ} \mathrm{C}$ & 16 & 21 & {$[9]$} \\
\hline Al-6.1Zn-2.35Mg-0.1Zr & $700 \mathrm{~h} / 160^{\circ} \mathrm{C}$ & $52 \pm 5$ & 49 & {$[9]$} \\
\hline Al-5.5Zn-1.2Mg-0.16Zr & $7 \mathrm{~h} / 170^{\circ} \mathrm{C}$ & 20 & 14 & {$[56]$} \\
\hline Al-5.5Zn-1.2Mg-0.16Zr & $7 \mathrm{~h} / 150^{\circ} \mathrm{C}$ & 11 & 9 & {$[56]$} \\
\hline Al-6.1Zn-2.3Mg-2.6Cu-0.1Zr & $16 \mathrm{~h} / 172^{\circ} \mathrm{C}$ & $19 \pm 3$ & 20 & {$[49]$} \\
\hline Al-6.7Zn-2.9Mg-1.9Cu-0.1Zr & $16 \mathrm{~h} / 172^{\circ} \mathrm{C}$ & $20 \pm 5$ & 20 & {$[49]$} \\
\hline 7475 (typical composition Al-5.7Zn-2.3Mg-1.6Cu-0.2Cr) & $1320 \mathrm{~h} / 160^{\circ} \mathrm{C}$ & 59 & 61 & {$[55]$} \\
\hline
\end{tabular}


Published as: Acta Mater., 2003, Vol. 51, pp. 5131-5150

\section{Figures}

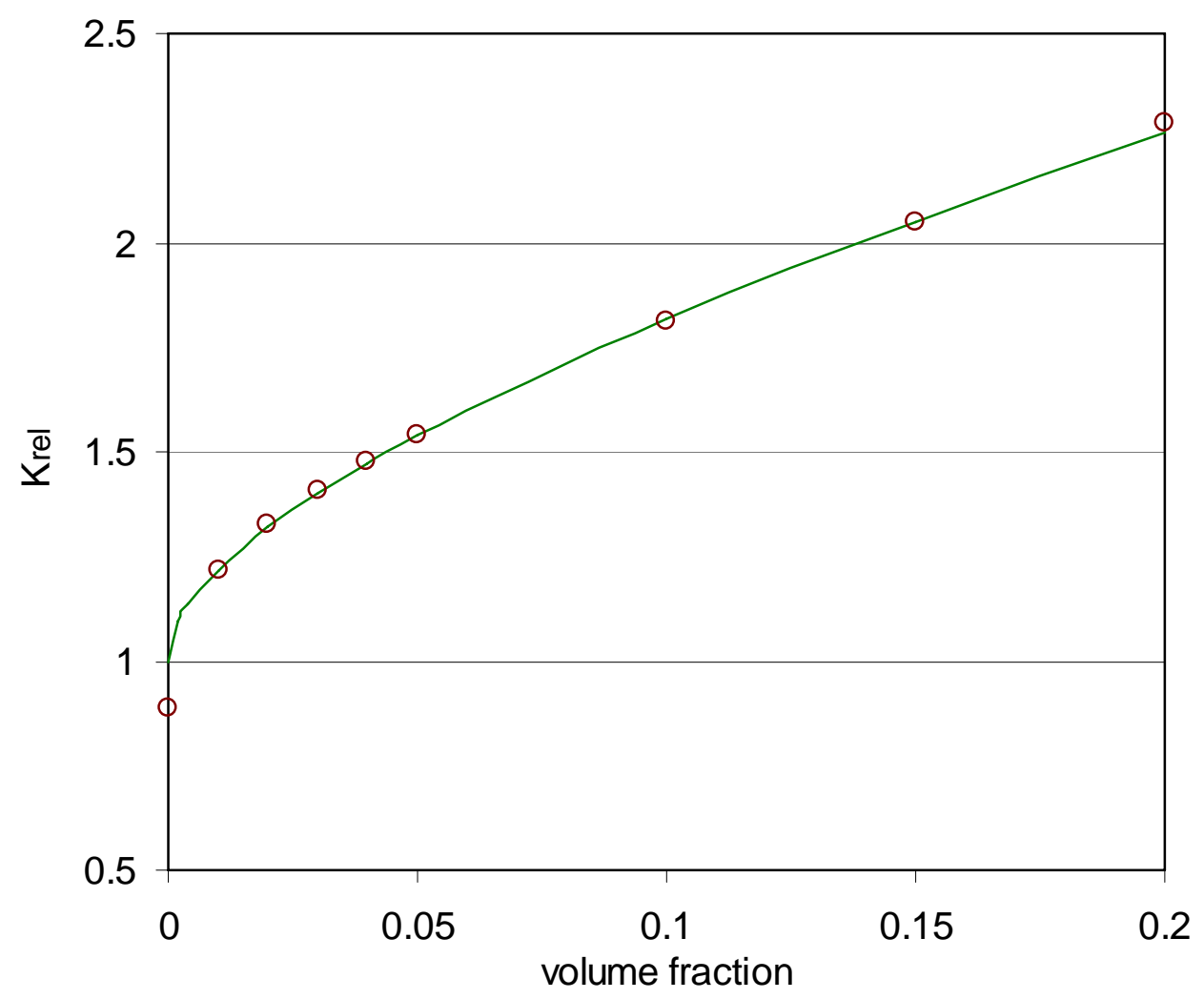

Fig. 1 The relative coarsening rates $K_{r e l}$ as determined by Marsh and Glicksman [38] fitted by Eq. 17.

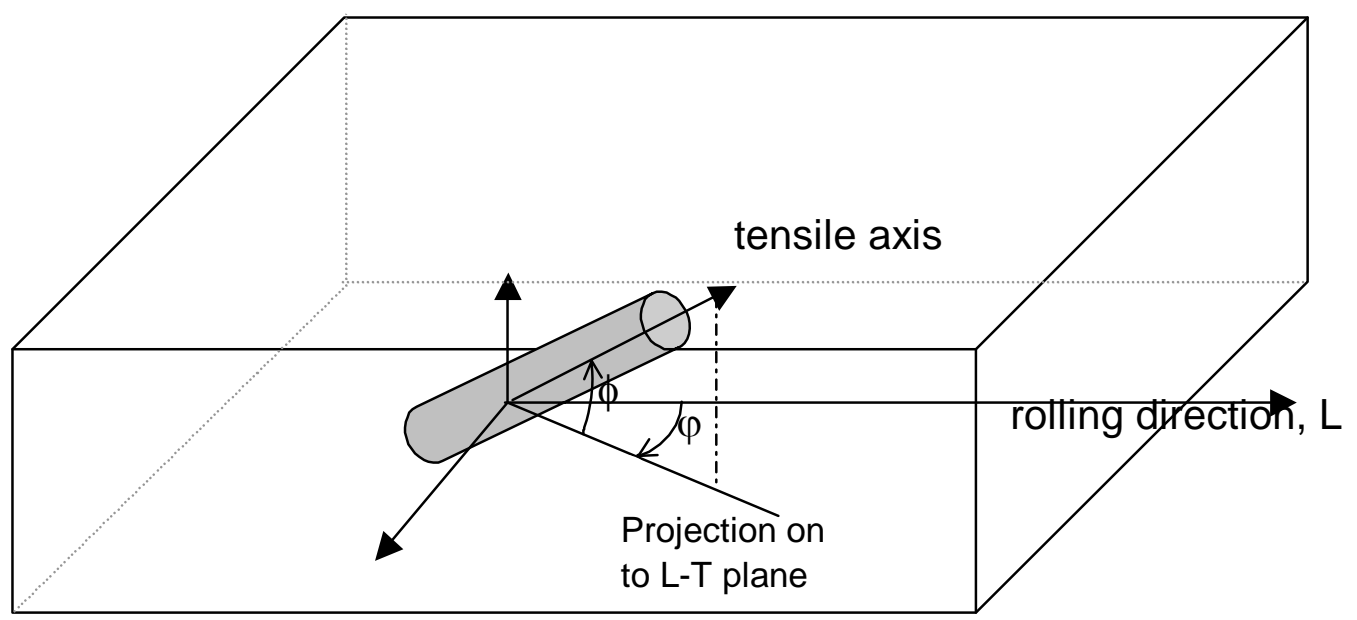

Fig. 2 Definition of the angles determining the orientation of a tensile axis relative to the rolled plate. 
Published as: Acta Mater., 2003, Vol. 51, pp. 5131-5150

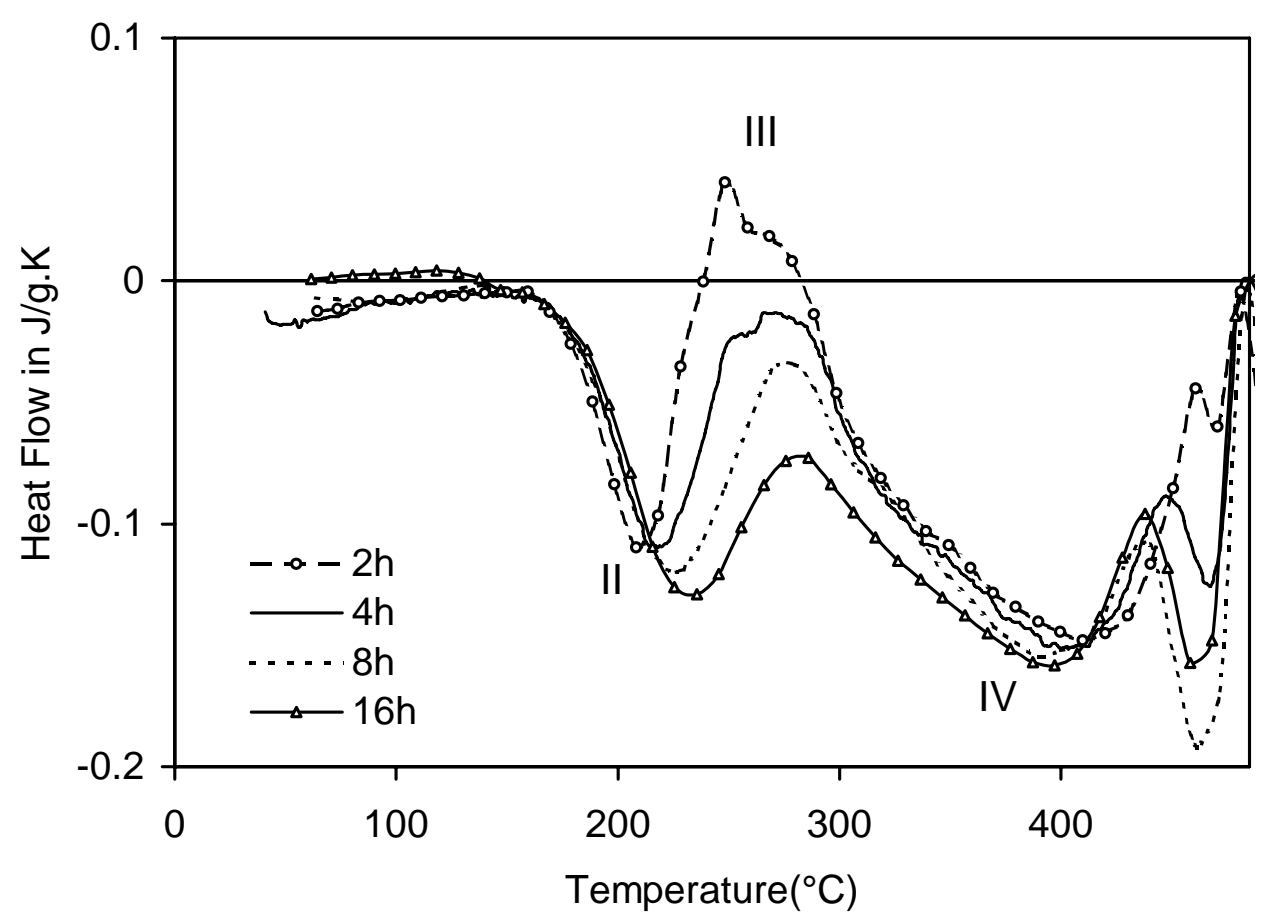

Fig. 3 DSC curves of the Al-6.1Zn-2.3Mg-2.6Cu-0.1Zr alloy aged for various times at $172^{\circ} \mathrm{C}$. Heating rate $10^{\circ} \mathrm{C} / \mathrm{min}$.

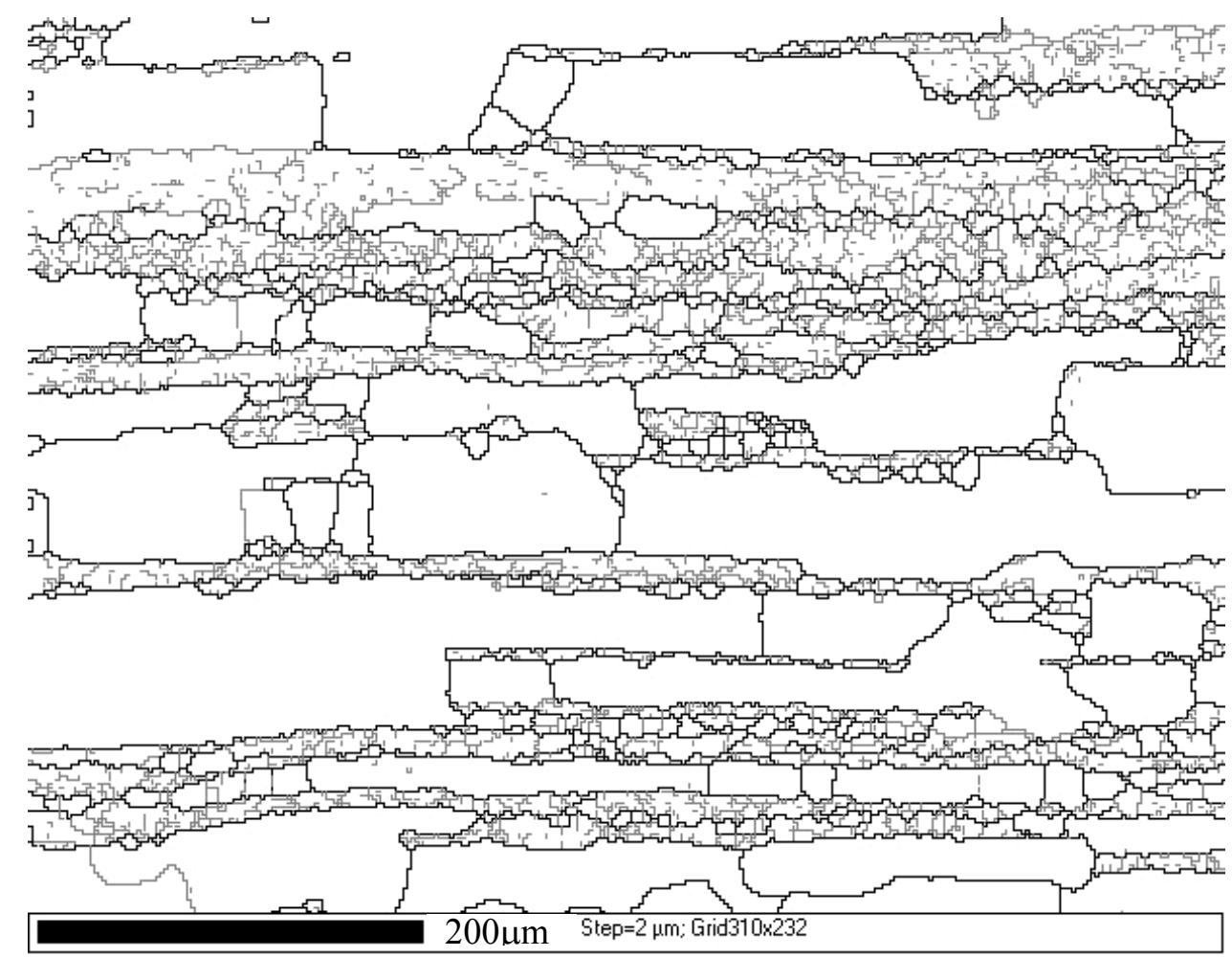

Fig. 4 Grain boundary map of the Zr-containing alloy Al-6.7Zn-2Mg-1.9Cu-0.1Zr (wt\%). 


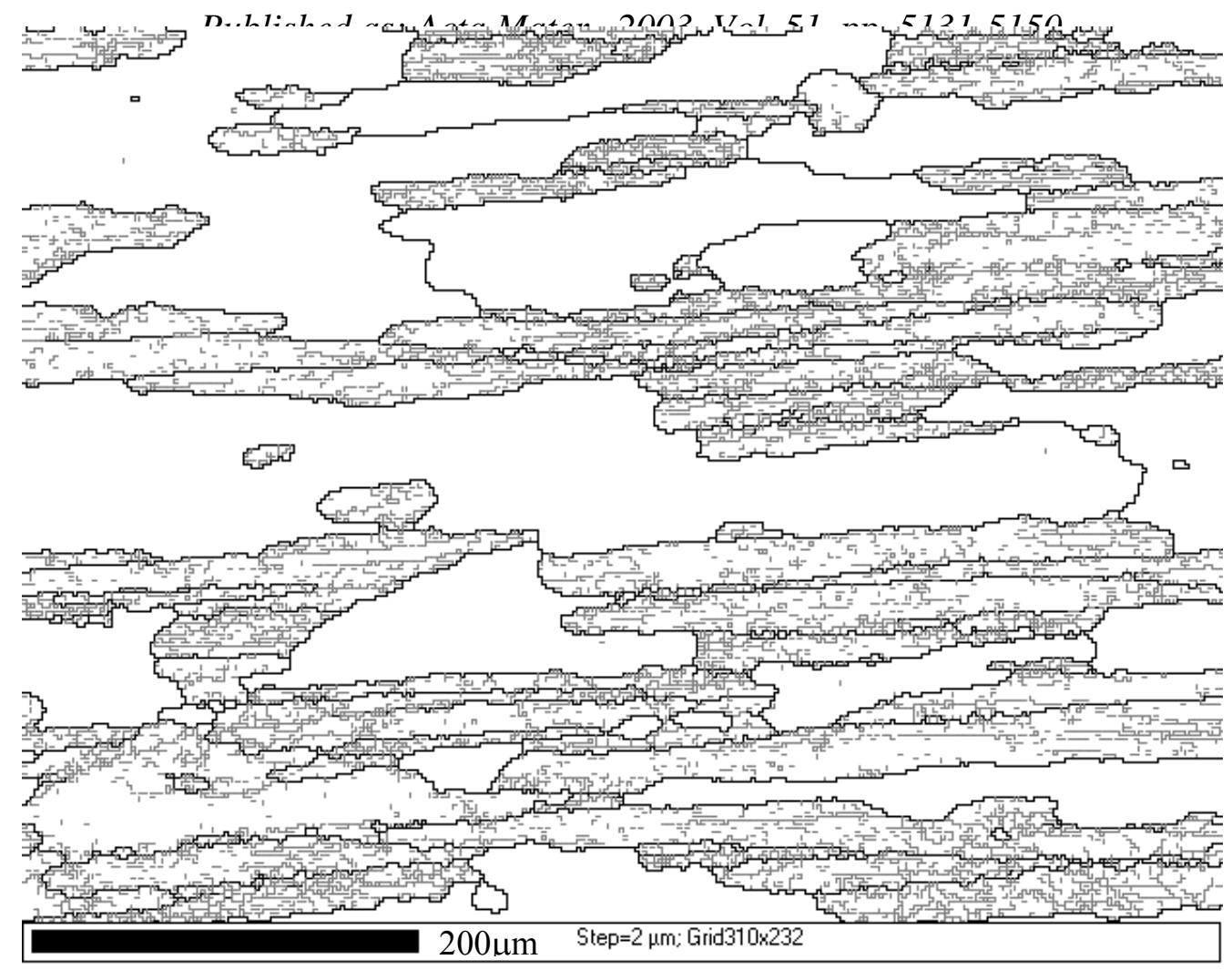

Fig. 5 Grain boundary map of Cr-containing alloy Al-5Zn-2.1Mg-1.1Cu- $0.2 \mathrm{Cr}(\mathrm{wt} \%)$.

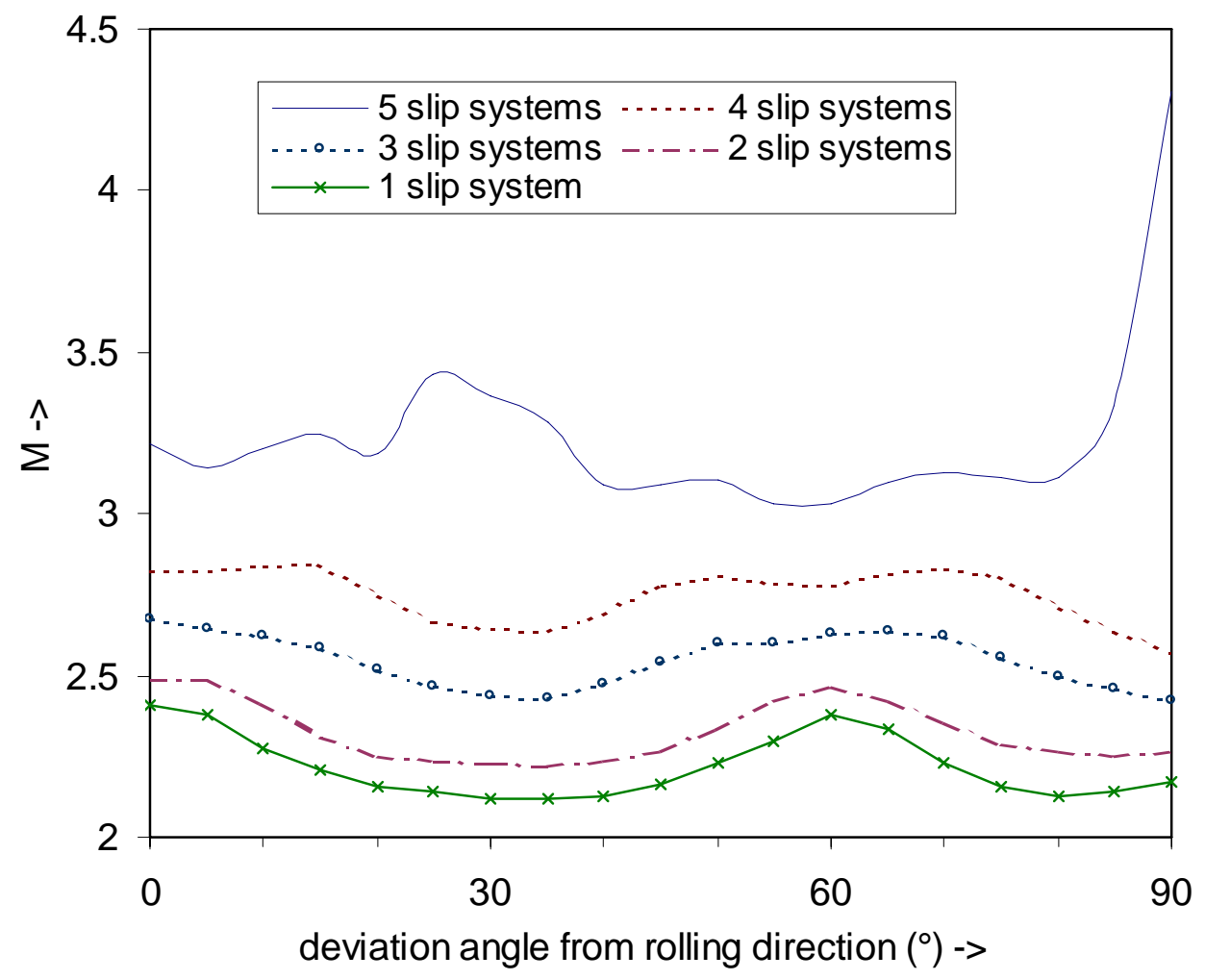

Fig. 6 Direction dependency of $M$ for Zr-containing alloy Al-6.7Zn-2Mg-1.9Cu-0.1Zr (wt\%) with different numbers of active slip systems. $M$ is plotted as a function of the angle between in-plate loading direction and rolling direction, $\phi$. 


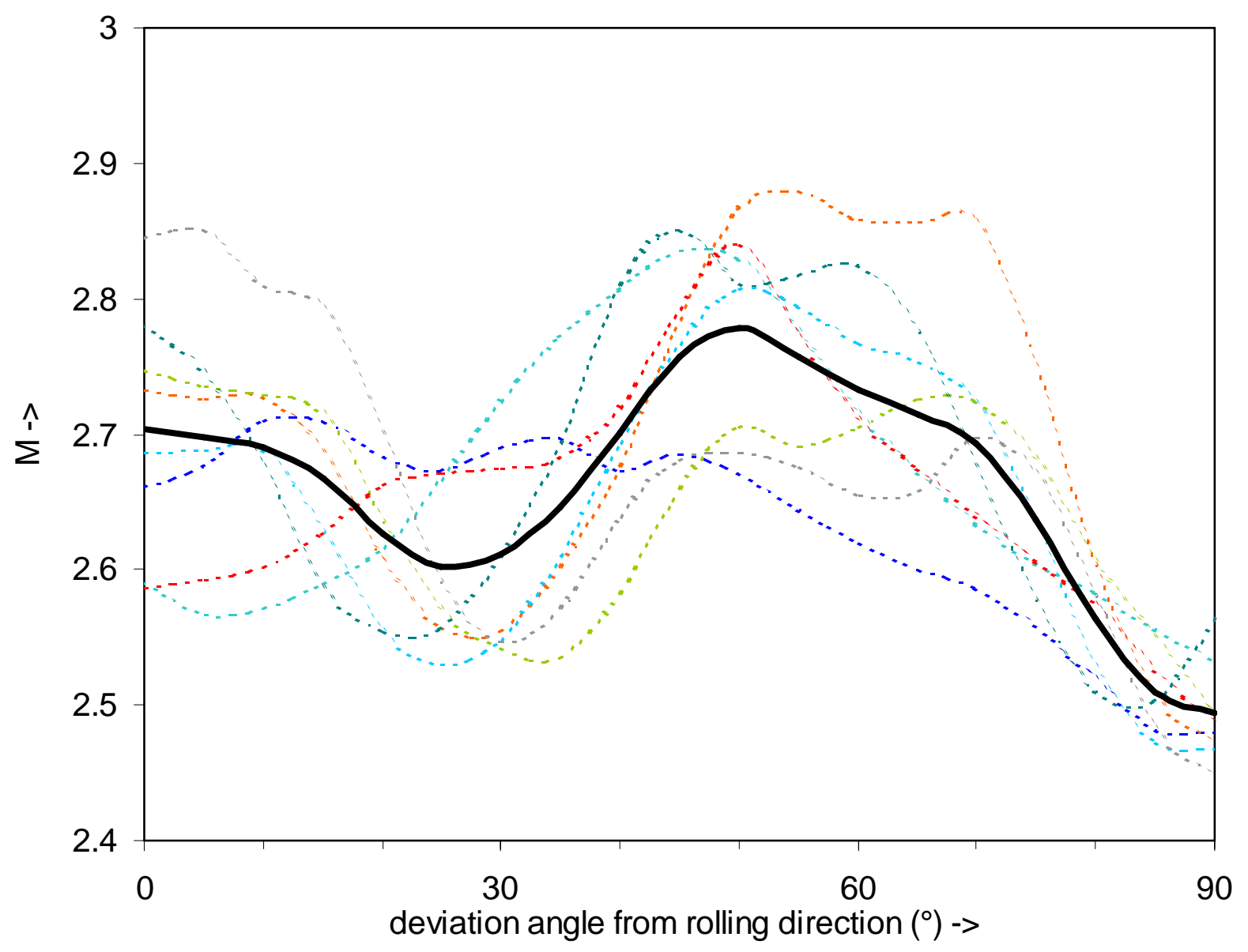

Fig. 7 Direction dependency of $M$ for $8 \mathrm{Zr}$-containing alloys, taking $M$ as the average of the cases where 3 and 4 slip systems are active (dotted lines). The solid line is the average value of $M$ for the 8 alloys. $M$ is plotted as a function of the angle between in-plate loading direction and rolling direction, $\phi$. 


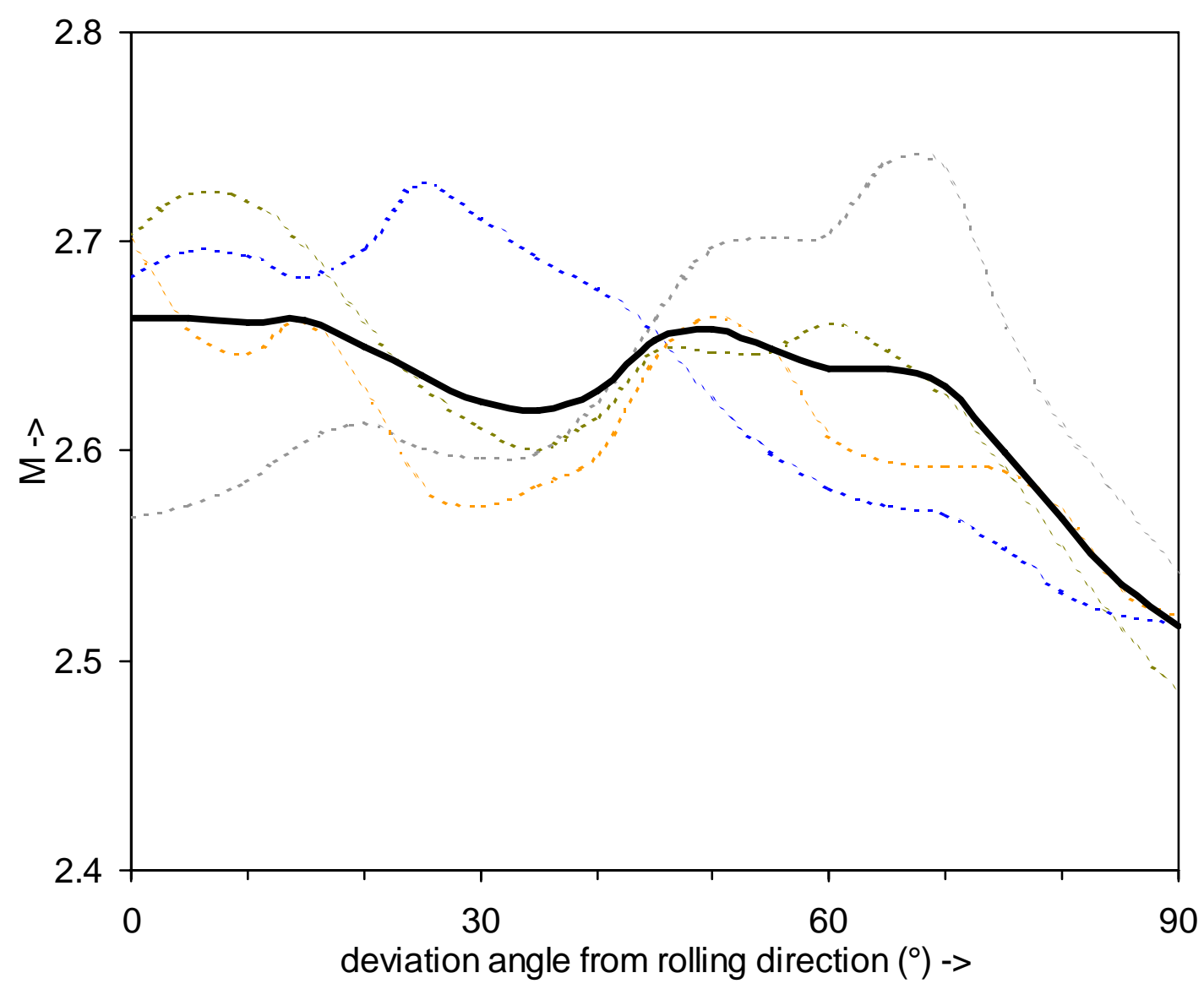

Fig. 8 Direction dependency of $M$ for three Cr-containing alloys, taking $M$ as the average of the cases where 3 and 4 slip systems are active. $M$ is plotted as a function of the angle between in-plate loading direction and rolling direction, $\phi$. 
Published as: Acta Mater., 2003, Vol. 51, pp. 5131-5150

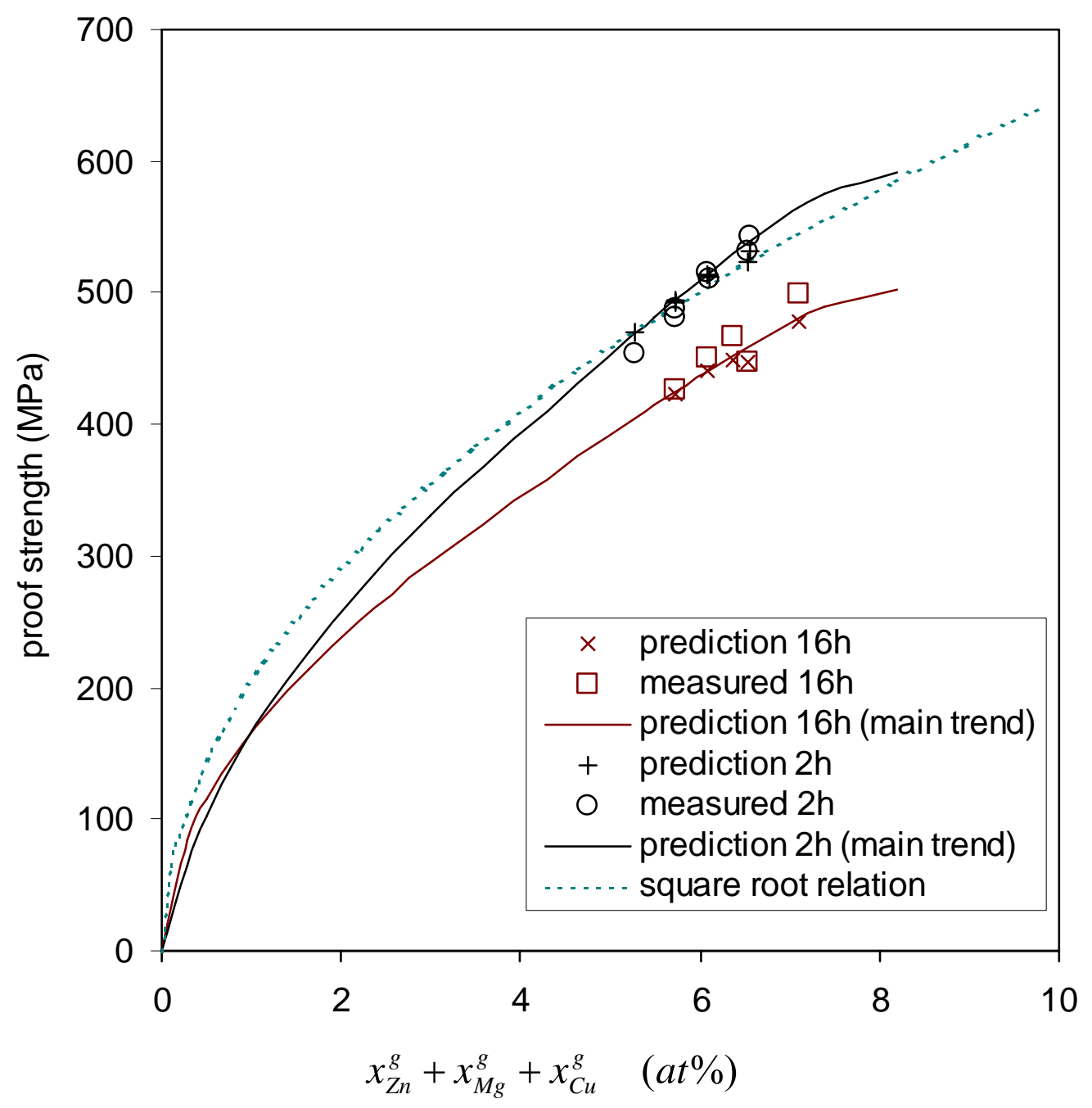

Fig. 9 Measured and predicted $0.2 \%$ proof strengths of various $\mathrm{Zr}$ containing alloys aged at $172^{\circ} \mathrm{C}$. The main trend is for $\mathrm{Zr}$ containing alloys with $\mathrm{Zn}: \mathrm{Mg}: \mathrm{Cu}$ contents of ratio 2.5:2:0.7 and 39\% recystallisation. 


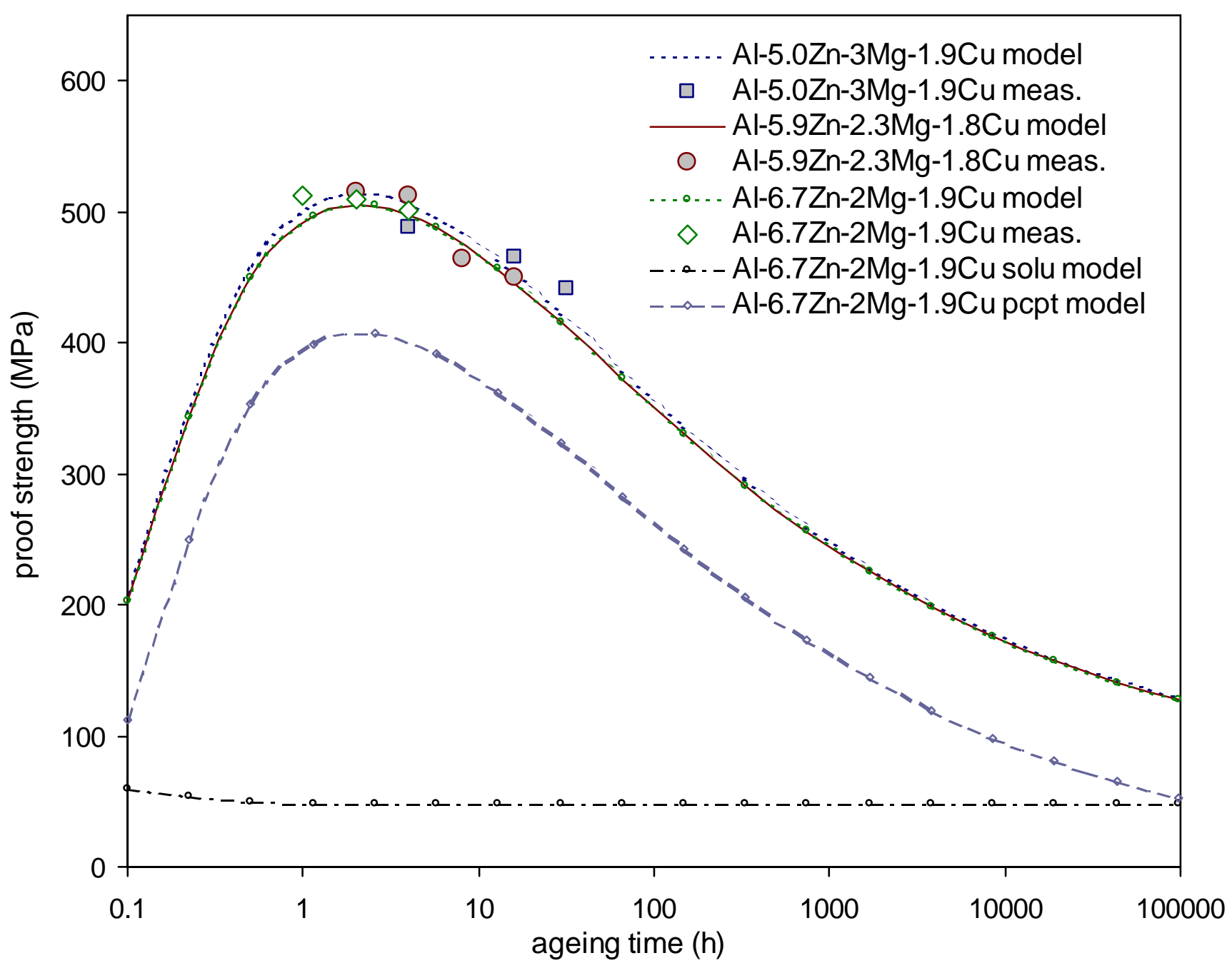

Fig. 10 Predicted and measured proof strengths for alloy three $\mathrm{Zr}$ containing alloys with very similar predicted strengths. Also presented are the predicted precipitate strengthening and solution strengthening contributions for one of the alloys. 
Published as: Acta Mater., 2003, Vol. 51, pp. 5131-5150

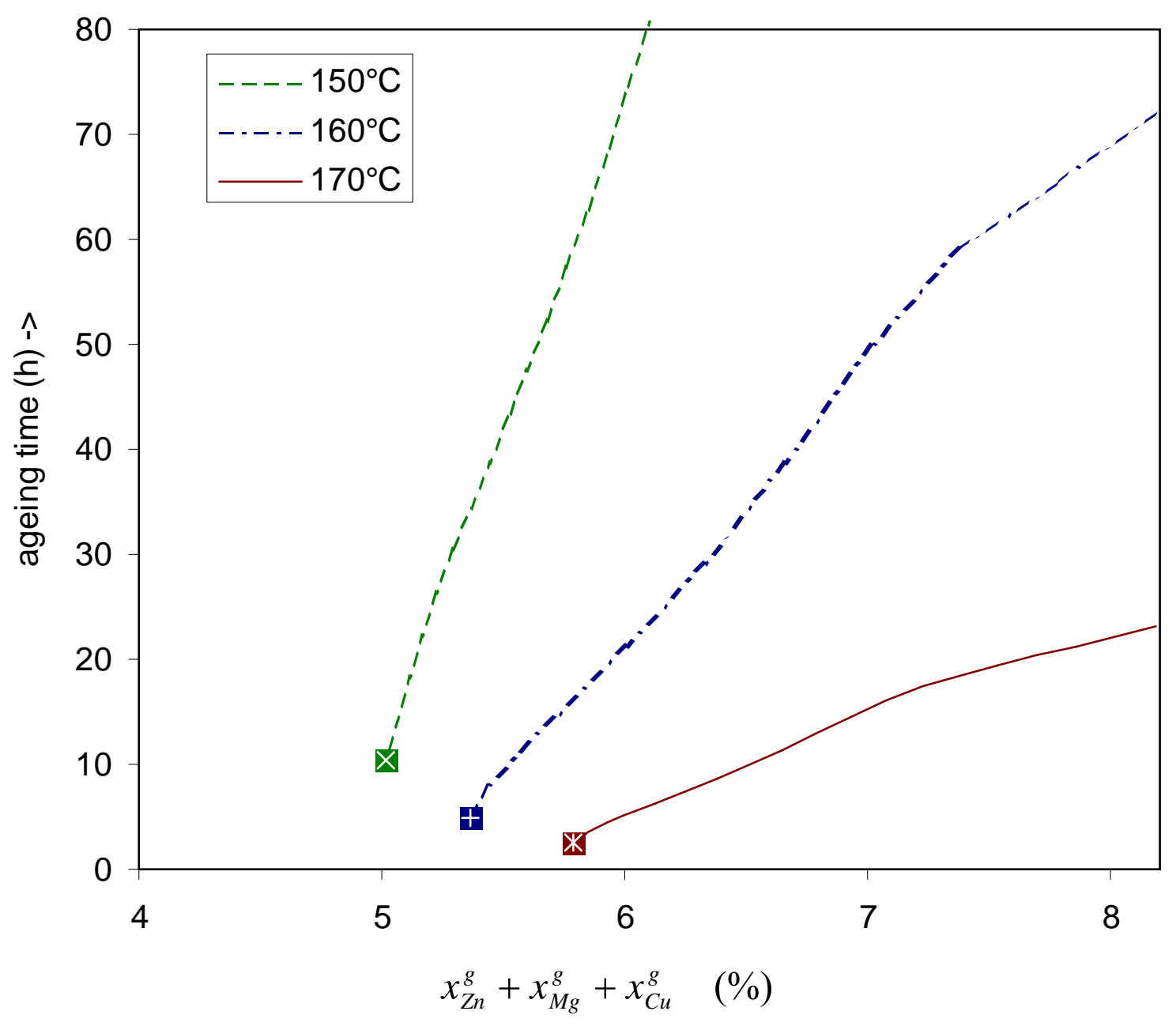

Fig. 11 Predicted ageing time at $150^{\circ} \mathrm{C}, 160^{\circ} \mathrm{C}$ and $170^{\circ} \mathrm{C}$ required to obtain a yield strength of $500 \mathrm{MPa}$ in the rolling direction as a function of the sum of atomic percentage $\mathrm{Zn}, \mathrm{Mg}$ and $\mathrm{Cu}$ alloy content for alloys with $\mathrm{Zn}: \mathrm{Mg}: \mathrm{Cu}$ contents of ratio 2.5:2:0.7 and 39\% recystallisation. 


\section{References}

[1] Shercliff HR, Ashby MF. Acta Metall. Mater. 1990; 38: 1789.

[2] Liu G, Zhang GJ, Ding XD, Sun J, Chen KH. Mater Sci. Eng. A 2003; 344: 113

[3] Deschamps A, Brechet Y. Acta Mater. 1999; 47: 293.

[4] Starink MJ, Wang P, Sinclair I, Gregson PJ. Acta Mater. 1999; 47: 3841.

[5] Starink MJ, Wang P, Sinclair I, Gregson PJ. Acta Mater. 1999; 47: 3855.

[6] Deschamps A, Solas D, Brechet Y. in Microstructure, Mechanical Properties and Process, Proc. of Euromat 99, vol. 3, Wiley-VCH, Weinhem, 2000, p. 121-132.

[7] Sainfort P, Sigli C, Raynaud GM. Mater. Sci. Forum 1997: 242: 25.

[8] Maloney SK, Hono K, Polmear IJ, Ringer SP. Scr. Mater. 1999; 41: 1031

[9] Deschamps A, Livet F, Brechet Y. Acta Mater. 1999; 47: 281.

[10] Cahn RW, Haasen P, Kramer EJ, Gomiero P. Materials Science and Technology-Structure and Properties of Nonferrous Alloys, VCH Publishers Inc., New York, USA, 1996.

[11] Wert JA. Scr. Metall. 1981; 15: 445.

[12] Engdahl T, Hansen V, Warren PJ, Stiller K. Mater. Sci. Eng. A 2002; 327: 59

[13] Li X, Starink MJ. Mater. Sci. Forum 2000; 331-337: 1071.

[14] Machler R, Uggowitzer PJ, Solenthaler C, Speidel MO, Mater. Sci. Technol. 1991; 7: 447.

[15] Li X. PhD thesis, University of Southampton, 2002

[16] Li X, Starink MJ. Mater. Sci. Techn. 2001; 17: 1324.

[17] Brown LM, Ham RK. in "Strengthening Methods in Crystals", ed. A. Kelly and R.B. Nicholson, Elsevier, Amsterdam, The Netherlands, 1971, p. 9.

[18] Schlieser C, Nembach E. Acta Metall. Mater. 1995; 43: 3983.

[19] Sachs E. Z. Ver. Deutsch. Ing. 1928; 72: 734.

[20] Taylor GI. J. Inst. Metals 1938; 62: 307.

[21] Hutchinson JW. Proc. R.. Soc. London A 1970; 319: 247

[22] Clausen B, Lorentzen T, Leffers T. Acta Mater. 1998; 46: 3087

[23] Morris AJ, Robey RF, Couch PD, Rios EDL. Mater. Sci. Forum 1997; 242: 181.

[24] Warner TJ, Shahani RA, Lassince P, Raynaud GM. 1997, $3^{\text {rd }}$ ASM Conf. On Synthesis, Processing and Modelling of Advanced Materials, Paris, France.

[25] Liang H, Chen SL, Chang, YA. Metall. Mater. Trans. A 1997; $28: 1725$.

[26] Liang P, Tarfa T, Robinson JA, Wagner S, Ochin P, Harmelin MG, Seifert HJ, Lukas HL, Aldinger F. Thermochim. Acta 1998; 314: 87.

[27] Villars P, Prince A, Okamoto H. 1995, ASM Handbook of Ternary Alloy Diagrams, ASM International, Materials Park, Ohio.

[28] Starink MJ, Li X. Metall Mater Trans A 2003; 34A: 899.

[29] Mondolfo LF. Aluminium Alloys: Structure and Properties, Butterworth \& Co. Ltd, London, England, 1976.

[30] Starink MJ, Gregson PJ. Scr. Metall. Mater. 1995; 33: 893.

[31] Starink MJ, Gregson PJ. Mater. Sci. Forum 1996; 217-222: 673.

[32] Strawbridge DJ, Hume-Rothery W, Little AT. J. Inst. Metals 1948; 74: 191. 
[33] Femminella OP, Starink MJ, Brown M, Sinclair I, Harris CJ, Reed PAS. ISIJ Int. 1999; 39: 1027

[34] Deschamps A, Bigot A, Livet F, Auger P, Brechet Y., Blavette D. Philosoph. Mag. 2001; 81: 2391.

[35] Starink MJ, Zahra AM. Thermochim. Acta 1997; 292: 159.

[36] Starink MJ. Acta Mater. 1998; 46: 3381.

[37] Poduri R, Chen LQ. Acta Mater. 1998; 46: 3915.

[38] Marsh SP, Glicksman ME. Acta mater. 1996; 44: 3761.

[39] Voorhees W, Glicksman ME. Acta metall. 1984; 32: 2013.

[40] Ardell AJ. Acta metall. 1972; 20: 61.

[41] Zhu AW, Starke EA. Acta Mater. 1999; 47: 3263

[42] Marthinsen K, Nes E. Mater. Sci. Eng. A 1997; 234-236: 1095

[43] Nes E, Marthinsen K. Mater. Sci. Eng. A 2002; 322: 176

[44] Nes E, Pettersen T, Marthinsen K. Scr. Mater. 2000; 43: 55

[45] Iraki I. J. Jpn. Inst. Light Metals 1993; 43: 1.

[46] Wagner JA, Shenoy RN. Metall. Trans. A 1991; 22A: 2809.

[47] Tempus G, Calles W, Scharf G. Mater. Sci. Techn. 1991; 7: 937.

[48] Park JK, Ardell AJ. Scr. Metall. 1988; 22: 1115

[49] Li X. PhD Thesis, University of Southampton, 2001.

[50] Dorward RC. Mater. Sci. Techn. 1999; 15: 1133.

[51] Starink MJ. J. Mater. Sci. 2001; 36: 4433.

[52] Starink MJ, Zahra AM. Phil. Mag. A 1998; 77: 187.

[53] Stiller K, Warren PJ, Hansen V, Angenette J, Gjønnes. J. Mater. Sci. Eng. A 1999: 270: 55.

[54] Engdahl T, Hansen V, Warren PJ, K. Stiller. Mater. Sci. Eng. A 2002; 327: 59.

[55] Poole WJ, Shercliff HR, Castillo T. Mater. Sci. Techn. 1997; 13: 897.

[56] Werenskiold JC, Deschamps A, Bréchet Y. Mater. Sci. Eng. A 2000; 293: 267.

[57] Starink MJ, Sinclair I, Reed PAS, Gregson PJ. Mater. Sci. Forum 2000; 331-337: 97

[58] Femminella OP, Starink MJ, Gunn SR, Harris CJ, Reed PAS. Mater. Sci. Forum 2000; 331-3: 1255

[59] Chistensen S, Sinclair I, Starink MJ. unpublished research, 2001

[60] Gunn SR, Brown M. in: Proc. IEEE International Workshop on Neural Networks for Signal Processing, Madison, Wisconsin, 1999

[61] Lebensohn R, Solas D, Canova G, Brechet Y. Acta Mater. 1996; 44: 315

[62] Poole WJ, Shercliff HR. Mater. Sci. Forum 1996; 217-222: 1287

[63] Starink MJ. Thermochim Acta 2003, in press

[64] Mittemeijer EJ. J. Mater. Sci. 1992; 27: 3977 